INTERNACIONAL

\title{
El estado de emergencia en el Perú democrático posconflicto: Un estudio preliminar de las normas de emergencia
}

\author{
The state of emergency in democratic post-conflict Peru: \\ A preliminary study on emergency laws

\section{Andrea Tafur Sialer (iD y Diego Quesada Nicoli (D) Universidad del Pacifico, Perú}

\begin{abstract}
RESUMEN El presente artículo estudia los estados de emergencia declarados en el Perú durante el periodo que inicia con el Gobierno de transición democrática instaurado en noviembre de 2000 hasta el 2018. En primer lugar, se encontró que el uso de los estados de emergencia aumentó progresivamente. Los autores afirman que la declaración de emergencia para controlar situaciones de orden interno -en las que el Gobierno limita el ejercicio de derechos y despliega a la Policía o a las Fuerzas Armadas- es una práctica normalizada donde los regímenes de emergencia son prorrogados reiteradas veces $y$, en ocasiones, incluso han alcanzado un estado de casi perpetuidad. Si bien la mayoría de estas emergencias han sido utilizadas para enfrentar el terrorismo, el estudio muestra que en el Perú posconflicto esta figura también ha sido utilizada de manera consistente en situaciones de conflictividad social. Por último, el texto revela que el Estado peruano, sin mayor justificación, ha venido aplicando estándares de uso de la fuerza propios del derecho internacional humanitario en aquellos estados de emergencia que delegan el control del orden interno a las Fuerzas Armadas, a pesar de no haber suficientes elementos para señalar que existe un conflicto armado.
\end{abstract}

PALABRAS CLAVE Estado de emergencia, suspensión de derechos, uso de la fuerza, derecho internacional de los derechos humanos, derecho internacional humanitario

ABSTRACT This paper studies the states of emergency declared in Peru during the period that begins with the democratic transition Government established in November 2000 until 2018. First, it was found that the use of states of emergency increased progressively. The authors argue that the declaration of emergency to control internal order situations -in which the Government limits the exercise of rights and deploys the Police or the Armed Forces- is a normalized practice where emergency regimes are extended 
several times and, in some cases, they have even reached a state of quasi-perpetuity. Although most emergencies have been used to fight terrorism, this paper shows that in post-conflict Peru this figure has also been consistently used in social conflicts. Finally, the article reveals that the Peruvian State has been applying standards of the use of force of International Humanitarian Law during the states of emergency where the control of the internal order is given to the Armed Forces, even though there does not seem to be enough grounds to argue the existence of an armed conflict.

KEYWORDS State of emergency, suspension of rights, use of force, international human rights law, international humanitarian law.

\section{Introducción: El estado (de la cuestión) de emergencia en el Perú}

La declaración de emergencia fue una pieza fundamental en la política contrasubversiva asumida por el Estado peruano durante el conflicto armado interno (CVR, 2013; Wright, 2015: 59). ${ }^{1}$ Los Gobiernos de turno - Belaúnde Terry (1980-1985), García (1985-1990) y Fujimori (1990-2000) - decretaron estados de emergencia en forma sistemática y semipermanente para combatir a Sendero Luminoso (Wright, 2015: 5862). En este sentido, la Comisión de la Verdad y Reconciliación del Perú (CVR) encontró que «el estado de emergencia se desnaturalizó y, de una institución excepcional que debía ser, se hizo permanente en distintas zonas del país, con la consiguiente suspensión de garantías previstas en las sucesivas constituciones vigentes. El carácter permanente que se le dio a la excepcionalidad, debilitó la democracia peruana y creó un clima propicio para las violaciones a los derechos humanos» (CVR, 2013: 222). Además, agregó que «las cifras de víctimas y de violaciones a los derechos humanos en los departamentos afectados [por el régimen de emergencia] crecieron exponencialmente, siendo este el período con la mayor cantidad de víctimas del conflicto» (CVR, 2013: 66).

La jurisprudencia de la Comisión Interamericana de Derechos Humanos (CIDH) y la Corte Interamericana de Derechos Humanos (Corte IDH) muestra una clara fotografía jurídica de este panorama: el Estado peruano ha sido constantemente responsabilizado por graves violaciones de derechos humanos y el uso arbitrario y desmedido de la fuerza durante el período de conflicto interno. La experiencia peruana - similar en distintas latitudes de la región- pone en evidencia que, en escenarios de violencia generalizada y de inestabilidad política, la restricción del ejercicio de

\footnotetext{
1. Cuando hacemos referencia al «conflicto armado interno»o «conflicto», nos referimos al conflicto armado no internacional que, de acuerdo con la Comisión de la Verdad y Reconciliación, se suscitó en el Perú en el período 1980-2000. Es importante resaltar que este conflicto se caracterizó por la estrategia terrorista de Sendero Luminoso en contra del Estado peruano. Véase Gurmendi (2019: 112).
} 
derechos individuales propia de los regímenes de excepción no respetó los límites constitucionales y convencionales de esta institución jurídica (Calveiro, 2008: 25-29).

El estado de emergencia en el Perú, pues, ha sido normalizado. ${ }^{2}$ El (ab)uso del estado de emergencia como herramienta jurídico-política, aunque alcanzó su punto más crítico a partir de la política contrasubversiva durante conflicto armado (Siles, 2015: 78-82), ha sido una constante histórica en la accidentada vida republicana del Perú (Siles, 2015: 84; Wright, 2015: 52-59). De hecho, los estados de excepción han sido utilizados desde la independencia del Perú, por Gobiernos civiles y militares, desde un paradigma represivo caracterizado por la restricción de derechos y la participación de las fuerzas armadas (Wright, 2015: 52-57). ${ }^{3}$

Esta normalización de la emergencia ha generado que, en diversos momentos de la historia peruana, no haya sido tan fácil distinguir la normalidad de la excepción (Wright, 2015: 62). Dos décadas después del conflicto armado interno, sabemos que el estado de emergencia continúa siendo utilizado como una práctica habitual del Estado peruano (Wright, 2015). Si bien la emergencia ha estado dirigida -al igual que en el período de conflicto armado- a enfrentar los remanentes terroristas y las actividades ilícitas vinculadas a éstos, en el siglo XXI también ha sido utilizada para atender fenómenos naturales (Grandez, 2012: 205-211; Wright, 2015: 72-73), combatir la delincuencia común (Siles, 2017: 125) y en escenarios de protestas sociales y ambientales (Saldaña y Portocarrero, 2017: 329-334; Wright, 2015: 64-65).

Es importante resaltar que, en 2020, la pandemia del covid-19 generó que el Gobierno declare el estado de emergencia para garantizar la inmovilización y el aislamiento social obligatorio, que a la fecha de cierre del artículo aún se encuentra en vigencia. El uso de los estados de emergencia como parte de la política estatal para enfrentar y controlar la pandemia, sin embargo, merece un análisis posterior propio.

Hasta el momento, aún no se cuenta con trabajos académicos que estudien de forma integral el uso que le ha dado el Estado peruano a esta herramienta jurídica en una etapa posconflicto, pero aún anterior al covid-19. Sin embargo, cabe destacar el análisis - no jurídico, por cierto- de Claire Wright (2015) sobre los estados de emergencia en la primera década del siglo XXI (2000-2010), el cual ha proporcionado importantes insumos para esta investigación. Por ello, el presente texto ofrece un

2. El concepto de normalización de la emergencia ha sido trabajado con anterioridad. Véase, por ejemplo, Ackerman (2007: 70) y Dyzenhaus (2002: 82-83).

3. De hecho, la independencia del Perú fue declarada por San Martín en el marco de un estado de excepción (Wright, 2015: 52). El siglo XIX estuvo caracterizado por las constantes luchas de poder y varios fallidos Gobiernos civiles, en los que, en el marco de los estados de excepción, se suspendieron garantías, mientras que las restricciones a la libertad de reunión y expresión en nombre de la patria eran una realidad (Wright, 2015: 54). Esta situación de inestabilidad política se prolongó durante el siglo XX, cuando los estados de excepción fueron utilizados tanto por Gobiernos civiles como militares para enfrentar, principalmente, situaciones de revuelta social y facilitar la suspensión de derechos (Wright, 2015: 56). 
estudio preliminar, desde el derecho, sobre el uso de los estados de emergencia por parte del Estado peruano durante más de dieciocho años (2000-2018), que inicia con la toma de mando del Gobierno de transición democrática liderado por Valentín Paniagua el 22 de noviembre de $2000 .{ }^{4}$ La metodología utilizada consistió en la recopilación, sistematización y análisis de 742 decretos supremos identificados que fueron utilizados por el Estado para declarar y prorrogar estados de emergencia.

Nuestra investigación está particularmente interesada en aquellas variables de los estados de emergencia que tienen un impacto en los derechos humanos en el Perú posconflicto. Y es que los estados de emergencia, además de estar limitados por garantías constitucionales mínimas de los derechos fundamentales, también comprometen las obligaciones internacionales del Estado peruano respecto del derecho internacional de los derechos humanos y, de ser el caso, la aplicación del derecho internacional humanitario. Por ello, el texto también relaciona el uso del estado de emergencia posconflicto con las normas de derecho internacional que resultan aplicables.

De esta forma, el artículo expone, en primer lugar, el diseño constitucional de los estados de excepción en el Perú. Luego, se muestran los resultados de nuestra investigación empírica sobre las normas de emergencia dictadas en el periodo materia de estudio. A partir de ello, se complejizan algunos hallazgos en cuanto a la normalización de la emergencia, la restricción de derechos fundamentales y el uso de la fuerza por parte agentes estatales. Por último, el texto reflexiona sobre algunas obligaciones internacionales que resultarían aplicables para el Perú durante los estados de emergencia y cómo ha venido (in)cumpliendo con ellas.

\section{Los regímenes de excepción en el orden constitucional peruano}

La Constitución del Perú (1993) incluye en el artículo 137 la prerrogativa de declarar estados de excepción ante las diferentes situaciones de «perturbación de la paz o del orden interno, de catástrofe o de graves circunstancias que afecten la vida de la nación» (estado de emergencia) o ante «invasión, guerra exterior, guerra civil, o peligro inminente de que se produzcan» (estado de sitio). 5 Autores como Siles y Wright in-

\footnotetext{
4. En adelante, cuando hagamos referencia al período estudiado «200o-2018», se entenderá que empieza en la fecha señalada.

5. «Artículo 137: El presidente de la República, con acuerdo del Consejo de Ministros, puede decretar, por plazo determinado, en todo el territorio nacional, o en parte de él, y dando cuenta al Congreso o a la Comisión Permanente, los estados de excepción que en este artículo se contemplan:

1. Estado de emergencia, en caso de perturbación de la paz o del orden interno, de catástrofe o de graves circunstancias que afecten la vida de la nación. En esta eventualidad, puede restringirse o suspenderse el ejercicio de los derechos constitucionales relativos a la libertad y la seguridad personales, la
} 
dican que la potestad de declarar un estado de excepción con restricción de derechos tiene sus orígenes incluso desde la propia fundación de la República peruana (Siles, 2015: 79; Wright, 2015: 52). Sin embargo, fue recién en la Constitución de 1933 cuando se sentaron las bases de la actual figura de los estados de excepción en el Perú como una prerrogativa del Ejecutivo que permite la restricción de ciertos derechos (Wright, 2015: 55). ${ }^{6}$ Con posterioridad, las constituciones de 1979 y 1993 incorporaron lo dispuesto por esta primera fórmula, ampliaron su definición e introdujeron características que moldearon la actual regulación.

Dado que los estados de sitio nunca han sido utilizados, el resto de la presente investigación tiene por objeto analizar los estados de emergencia.

El texto constitucional contiene una definición del estado de emergencia que ha sido calificada como vaga y ambigua (Wright, 2015: 61). En efecto, la definición que propone la Constitución del estado de emergencia es amplia, flexible y dócil: utiliza conceptos jurídicos indeterminados (¿cómo se materializa la «perturbación de la paz o del orden interno», la "catástrofe» o las "graves circunstancias que afectan la vida de la nación»?) que permiten que esta prerrogativa constitucional sea utilizada con discrecionalidad por la autoridad de Gobierno.

La competencia para declarar o prorrogar los estados de emergencia corresponde al presidente de la República, con el refrendo del Consejo de Ministros. Si bien la norma constitucional establece el deber de «dar cuenta al Congreso», el Ejecutivo entiende esta obligación como un simple deber de notificación en virtud del cual remite una copia del decreto supremo al Congreso. Éste no recibe mayor trámite en sede parlamentaria. Asimismo, el artículo 200 de la Constitución Política del Perú (1993) establece que los jueces no pueden cuestionar las razones por las que se dicta un es-

inviolabilidad del domicilio, y la libertad de reunión y de tránsito en el territorio comprendidos en los incisos 9, 11 y 12 del artículo 2 y en el inciso 24, apartado f del mismo artículo. En ninguna circunstancia se puede desterrar a nadie.

EL plazo del estado de emergencia no excede de sesenta días. Su prórroga requiere nuevo decreto. En estado de emergencia las Fuerzas Armadas asumen el control del orden interno si así lo dispone el presidente de la República.

2. Estado de sitio, en caso de invasión, guerra exterior, guerra civil, o peligro inminente de que se produzcan, con mención de los derechos fundamentales cuyo ejercicio no se restringe o suspende. El plazo correspondiente no excede de cuarenta y cinco días. Al decretarse el estado de sitio, el Congreso se reúne de pleno derecho. La prórroga requiere aprobación del Congreso».

6. Es importante indicar que en los artículos 35 y 36 de la Constitución de 1920 se establecía que las garantías individuales no podían ser suspendidas por ninguna ley ni autoridad, incluso en contextos en que peligre la seguridad interior o exterior del país. Sin embargo, como lo señala Wright, en la práctica el régimen de Leguía no respetó lo señalado por la Constitución promulgada por su propio Gobierno, persiguiendo y encarcelando a disidentes políticos, estudiantes y personas indígenas (Wright, 2015: 54-55). 
tado de emergencia.7 Por lo tanto, la declaración de estado de emergencia en el Perú por el Ejecutivo no tiene mecanismos reales y efectivos de contrapeso o revisión. ${ }^{8}$

Como habíamos adelantado, los estados de emergencia tienen importantes consecuencias en los derechos humanos que merecen ser advertidas y complejizadas. Por este motivo, resulta indispensable profundizar en dos aspectos de la declaración de emergencia que involucran las obligaciones internacionales del Estado peruano: i) la facultad de restringir o suspender algunos derechos constitucionales; y ii) la participación de la Policía Nacional del Perú (PNP) y de las Fuerzas Armadas (FFAA) en el control del orden interno y el uso de la fuerza.

Por una parte, la norma constitucional autoriza una mayor limitación en el ejercicio de ciertos derechos durante la situación excepcional de «emergencia» que se busque enfrentar. El texto constitucional permite restringir o suspender ${ }^{9}$ el ejercicio de los derechos a la: i) libertad y seguridad personal, ii) inviolabilidad del domicilio, iii) libertad de reunión y iv) libertad de tránsito. Para hacer efectiva la restricción o suspensión, es necesario que el decreto supremo especifique explícitamente los derechos objeto de esta limitación extraordinaria (Chirinos Soto, 1997: 283). Los jueces constitucionales podrán evaluar de forma posterior, en los procesos de amparo y habeas corpus, que la actuación de las autoridades estatales en la restricción o suspensión del ejercicio de derechos se ajuste a los criterios de razonabilidad y proporcionalidad.

Por otra parte, el estado de emergencia permite delegar el control del orden interno de la zona objeto de la norma de forma temporal y extraordinaria a las Fuerzas Armadas cuando así se disponga de forma expresa, en lugar de permanecer a cargo de la Policía Nacional, que es la encargada (ordinaria) de garantizar el orden interno. ${ }^{10}$

7. «Artículo 200. [...] Cuando se interponen acciones de esta naturaleza en relación con derechos restringidos o suspendidos, el órgano jurisdiccional competente examina la razonabilidad y proporcionalidad del acto restrictivo. No corresponde al juez cuestionar la declaración del estado de emergencia ni de sitio».

8. Esto no quiere decir que eventualmente el Congreso pueda ejercer un control más acucioso mediante la formación de comisiones investigadoras o un control político de esta prerrogativa. Es quizás la normalización de la emergencia en el Perú lo que genera que la institución que debería ejercer un contrapeso y un rol fiscalizador en la práctica no lo haga.

9. Adelantamos que hablamos de suspensión (así, en itálicas), pues ésta no implica, en un significado literal del vocablo, la anulación del ejercicio de un derecho durante un período de tiempo. Por el contrario, esta suspensión implica un nivel mayor de la restricción regular del ejercicio de un derecho. Véase Abad (2004: 52) y Defensoría del Pueblo (2003: 110).

10. A pesar de que el texto constitucional peruano hace referencia al orden interno, este concepto carecía de un contenido jurídico determinado hasta la decisión del Tribunal Constitucional del Perú en 2004, que tímidamente dibujó sus contornos. Así, la decisión consideró que este concepto comprendía tres aspectos en particular: «a) Seguridad ciudadana: esto implica la protección de la vida, de la integridad física y moral de las personas, el respeto al patrimonio público y privado, entre otros; b) estabilidad de la organización política: esto se refiere al mantenimiento de la tranquilidad, quietud y paz pública, 
De acuerdo con la legislación peruana, el nivel de uso de la fuerza permitido por parte de los agentes estatales en un estado de emergencia depende de la institución a cargo del orden interno. Así, existe un estándar jurídico de uso de la fuerza para la Policía Nacional (Decreto Legislativo 1.186, de 2015) y otro distinto a las Fuerzas Armadas (Decreto Legislativo 1.095, de 2010) cuando el régimen de emergencia le delega el control del orden interno. Sin embargo, las Fuerzas Armadas también pueden brindar una tarea de apoyo a la Policía en el control del orden interno. En este escenario, cuando las Fuerzas Armadas apoyan a la Policía, tanto fuera como dentro de un estado de emergencia, se encuentran sujetos a las normas de uso de la fuerza de los agentes policiales.

Por último, no existe en el Perú un marco legal o normativo coherente de la institución de emergencia. ${ }^{11}$ Como señala Siles (2017: 129, 133-134), encontramos leyes y disposiciones legales dispersas, fragmentarias e incompletas, contenidas en distintos instrumentos que abordan aspectos específicos o parciales de la materia. Sin embargo, ninguna de estas normas otorga verdadero contenido a lo establecido en el artículo 137 de la Constitución (1993) ni delimita los alcances de la norma constitucional. El propio Tribunal Constitucional en 2009 ha exhortado al Congreso a adoptar una legislación en materia de estados de excepción (expediente 00002-2008-PI/TC, considerando $\left.31 .^{\circ}\right)$. A la fecha, sin embargo, no se le ha otorgado mayor desarrollado legislativo a dicha cláusula constitucional de emergencia, cuya literalidad dice muy poco.

\section{La aplicación del estado de emergencia en el Perú}

Los hallazgos del presente estudio confirman que los estados de emergencia en el Perú han sido utilizados con dos grandes propósitos: i) atender (o prevenir) las consecuencias de fenómenos naturales y ii) garantizar el orden interno. La figura 1 muestra el universo de decretos supremos que declaran o prorrogan estados de emergencia

así como el respeto hacia la legítima autoridad pública; y c) resguardo de las instalaciones y servicios públicos esenciales: esto incluye las edificaciones públicas e instalaciones que cubren necesidades vitales y primarias de la comunidad, tales como el agua, la energía eléctrica, entre otros» (expediente oo172003-AI/TC, considerando octavo).

11. Sólo los estados de emergencia que responden a desastres naturales cuentan con una norma que regula el procedimiento para su declaración: la ley que crea el Sistema Nacional de Gestión del Riesgo de Desastres (SINAGERD), Ley 29.664 de 2011. No obstante, es importante señalar los avances de coordinación internacional en materia de prevención, planificación de medidas y reducción de riesgos a consecuencia de desastres naturales, como es el caso del Marco de Sendai para la Reducción del Riesgo de Desastres 2015-2030. Mediante este Marco se busca prevenir la aparición de nuevos riesgos de desastres y reducir los existentes implementando medidas que prevengan y reduzcan el grado de exposición a las amenazas y la vulnerabilidad a los desastres, para aumentar la preparación para la respuesta y la recuperación (párrafo 17). 


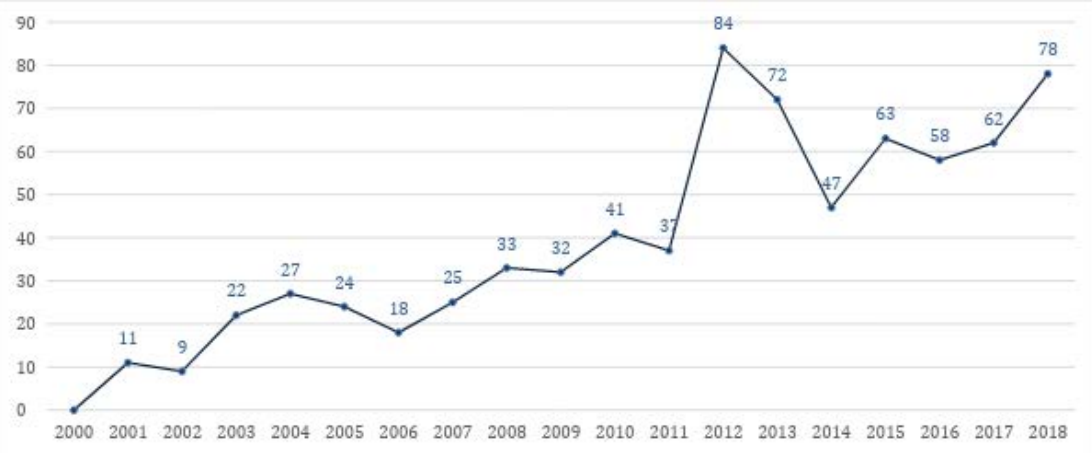

Figura 1. Decretos supremos por año (2000-2018). Fuente: Elaboración propia.

expedidos por año, ${ }^{12}$ mientras que la figura 2 revela la relación entre aquéllos destinados a atender fenómenos naturales y aquéllos sobre alteraciones al orden interno.

En primer lugar, no podemos dejar de hacer notar que el número total de decretos supremos, tanto para fenómenos naturales como para orden interno, presenta una marcada tendencia al alza desde el inicio del periodo estudiado. ${ }^{13}$

A primera vista, podemos advertir que la institución de emergencia ha sido utilizada con bastante mayor frecuencia para atender casos de fenómenos naturales. Sólo durante un período de tres años (2006-2008) el número de los estados de emergencia de orden interno superó al de fenómenos naturales, producto de una disminución de estos últimos durante dicho lapso de tiempo.

De un total de 742 decretos supremos identificados en el periodo estudiado, 272 se refieren al control del orden interno. De esta forma, la necesidad de garantizar el orden interno ha justificado poco más de un tercio $(36,7 \%)$ del total de decretos supremos sobre estados de emergencia.

La figura 2 muestra que el número de decretos supremos por orden interno ha sido, aunque con una marcada tendencia al alza, relativamente constante. Por ello, los picos que se observan en la figura 1 coinciden con aquellos originados por fenómenos naturales que muestra la figura 2. Es así como, en los años en los que se registró un incremento radical de decretos supremos - por ejemplo, en 2012, 2013,

12. Si bien en el año 2000 se expidieron cinco decretos supremos declarando o prorrogando estados de emergencia (todos relacionados a fenómenos naturales), nuestra investigación recién toma en cuenta aquellos expedidos con posterioridad al inicio del mandato del presidente Valentín Paniagua, el 22 de noviembre.

13. Por un lado, el incremento de aquellas emergencias por fenómenos naturales podría encontrar una explicación en el constante deterioro ambiental producto del calentamiento global, fenómenos meteorológicos extraordinarios o simplemente un mayor uso por parte del Gobierno para enfrentar situaciones atípicas. Por otro lado, no obstante, el aumento de las emergencias por orden interno a pesar de la distancia temporal con el conflicto armado resulta llamativa. 


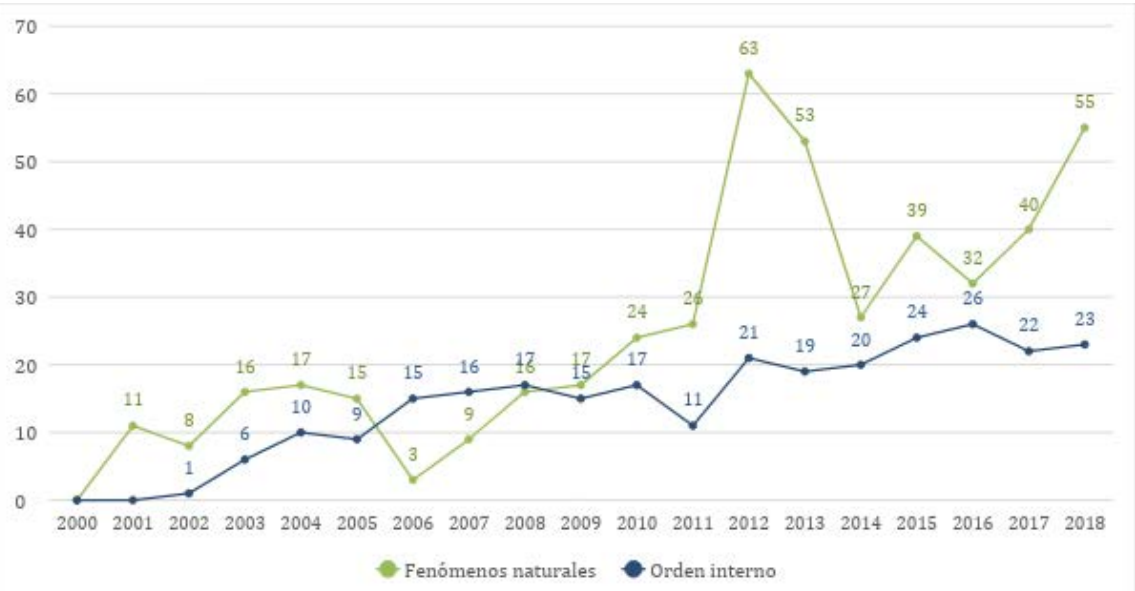

Figura 2. Decretos supremos por año según su propósito (2000-2018). Fuente: Elaboración propia.

2015 y 2018 - fue causado casi exclusivamente por aquellas declaraciones relativas a fenómenos naturales. Aunque la emergencia por orden interno ha sido transversal a todos los Gobiernos, sí se puede identificar que durante el Gobierno de Alan García (2006-2010) se produce un primer aumento significativo (Wright, 2015: 64) que es luego continuado e intensificado por los gobiernos de Ollanta Humala, Pedro Pablo Kuczynski y Martín Vizcarra.

Los estados de emergencia sobre fenómenos naturales, cabe precisar, no disponen la limitación o suspensión de derechos; ni tampoco dispone un mayor control de la Policía ni de las Fuerzas Armadas. En cambio, este tipo de estados de emergencia han tenido por finalidad desplegar medidas urgentes de ayuda humanitaria, decretar la interrupción de servicios o sectores económicos y la exoneración de los procedimientos de contratación pública para ejecutar presupuesto de forma excepcional (Wright, 2015: 72-73). Si bien advertimos que éstos merecen mayor atención debido a la frecuencia con la que vienen siendo utilizados, la presente investigación tiene por objeto profundizar en aquellas situaciones en que se produce una restricción extraordinaria de derechos fundamentales con el objetivo de garantizar el orden interno en una etapa posconflicto.

\section{Los estados de emergencia por orden interno}

A partir de los 272 decretos supremos sobre orden interno identificados, la presente investigación los ha organizado en 60 estados de emergencia en el anexo 1 de acuerdo con el texto de las propias normas. ${ }^{14}$

14. Los estados de emergencia del anexo 1 han sido distinguidos a partir de la propia referencia de los 
Los resultados del uso del estado de emergencia posconflicto ponen en evidencia que esta institución es una práctica normalizada en el Perú. Como fue advertido, durante el período 2000-2018 los Gobiernos de turno han utilizado, cada vez con mayor frecuencia, el estado de emergencia para intentar controlar el orden interno. Como será mostrado en esta sección, durante el período 2000-2018, determinadas zonas del país han estado bajo un estado de emergencia de forma semipermanente, en especial aquéllas donde han persistido células terroristas; mientras que la emergencia también es una herramienta recurrente para las situaciones de conflictividad social, sobre todo las relacionadas con la extracción de recursos naturales, ${ }^{15} \mathrm{y}$ para otros motivos menos recurrentes, como la seguridad ciudadana y la criminalidad transfronteriza. Para ello, los instrumentos de emergencia han decretado la suspensión del ejercicio de derechos constitucionales y se ha desplegado la participación de la Policía y las Fuerzas Armadas.

A continuación, mostramos algunos hallazgos en cuanto a: i) los plazos de los estados de emergencia, ii) los motivos de emergencias posconflicto, iii) las regiones en emergencia, iv) la suspensión de (todos) los derechos constitucionales, y v) la participación de la Policía, las Fuerzas Armadas y el uso de la fuerza.

\section{Los plazos de emergencia}

Del estudio de los decretos supremos se advierte que los estados de emergencia, en su abrumadora mayoría, han utilizado el plazo máximo permitido por la Constitución (6o días) y se han prorrogado repetidas veces. ${ }^{16} \mathrm{El}$ límite constitucional, entonces, ha representado en la práctica una mera formalidad, en tanto se pueden prorrogar, como ha sucedido, de forma irrestricta. Del total de 60 estados de emergencia, casi la mitad (26) fueron prorrogados más allá de su plazo inicial, es decir, por lo menos una vez. En promedio, cada uno de los estados de emergencia fue prorrogado 3,5 veces. Sin embargo, cuando dejamos de lado aquéllos que no fueron prorrogados, el promedio supera las 8 veces. ${ }^{17}$

decretos supremos, en el sentido de si se trata de una nueva declaración o de una prórroga. A primera vista, parecería que en ciertos escenarios existe más de un estado de emergencia sobre el mismo espacio geográfico. Sin embargo, se trata de estados de emergencia cuyo plazo fue interrumpido. En aquellos casos, el plazo legal llegó a su fin y, posteriormente, el Gobierno decidió reanudar con la situación de emergencia. Ante la imposibilidad de hacer una prórroga, se tuvo que declarar un nuevo estado de emergencia.

15. Véase infra, capítulo «Las emergencias posconflicto».

16. Sin embargo, un número significativo de decretos también utilizaron el plazo de 30 días y, sólo en forma excepcional, plazos más breves.

17. Esta cifra está influenciada por: i) ciertos estados de emergencia que tuvieron un número de prórrogas muy superior a los demás, como EE11 (32), EE33 (22), EE34 (30), EE36 (26) (anexo 1); y ii) los seis estados de emergencia que sólo fueron prorrogados una vez. Cabe resaltar que estos resultados omiten 
Esta práctica de constantes prórrogas ha generado un gran peligro jurídico en la vigencia de los estados de emergencia: once estados de emergencia cometieron errores en las fechas de inicio las prórrogas (EE2, $\mathrm{EE}_{3}, \mathrm{EE}_{4}, \mathrm{EE} 7, \mathrm{EE} 10, \mathrm{EE}_{14}, \mathrm{EE}_{20}, \mathrm{EE}_{30}$ $\mathrm{EE}_{33}, \mathrm{EE}_{52}$ y EE56). Este hecho causó que existan días en el transcurso del estado de emergencia en los cuales no estuvo vigente el régimen de excepción por una confusión en las fechas de inicio introducidas por las prórrogas. Esta situación se puede apreciar especialmente en estados de emergencia de larga duración, en que existe una gran cantidad de prórrogas. Por lo tanto, en aquellos días, la suspensión - en estricto- no sería efectiva y cualquier restricción de derechos debería ser evaluada bajo los criterios jurídicos ordinarios de normalidad constitucional.

Sin embargo, la real envergadura de las declaraciones de emergencia y sus prórrogas sólo puede apreciarse a partir de la situación que motivó el estado de emergencia. Por ello, a continuación, analizamos cuáles han sido aquellas situaciones de emergencia en el Perú posconflicto.

\section{Las emergencias posconflicto}

El texto de los decretos supremos es virtualmente idéntico en todos los casos. Más que un análisis contextualizado que amerite una respuesta estatal específica en un marco de excepción constitucional, la práctica de los Gobiernos de turno ha sido elaborar normas de emergencia de forma automatizada y laxa, cuya literalidad no justifica los elementos fácticos que, de forma particular, sustentan aquella declaración o prórroga.

Por ello, descifrar la justificación de cada uno de los estados de emergencia declarados en el Perú durante el período estudiado no ha sido una tarea sencilla. Los decretos supremos utilizados, en su abrumadora mayoría, no dan luces sobre las razones que motivan la declaración, prórroga o cualquier otra modificación al estado de emergencia. Por el contrario, utilizan un mismo discurso superficial que no describe en lo absoluto la situación que pretenden abordar. Por ejemplo, hacen constantes referencias a actos de violencia, alteraciones al orden público y actividades ilícitas. Sin embargo, nunca señalan a cuáles de ellas se refieren.

De hecho, el segundo estado de emergencia por orden interno decretado durante el periodo de estudio (EE2) - y el único instaurado en todo el territorio nacional-

\footnotetext{
o dejan de lado que muchos de los estados de emergencia fueron interrumpidos por días de normalidad para luego declararse un nuevo estado de emergencia en la misma área y por los mismos motivos. Este fenómeno generó la formación de «nuevos» estados de emergencia para atender virtualmente la misma situación en el mismo territorio, lo cual debe ser advertido en la lectura del anexo 1; por ejemplo, los EE18, EE2o, EE26, EE30 y EE33 (Marañón); EE3, EE4, EE11, EE34 y EE47 (Huanta y La Mar); EE5 y EE7 (Carabaya); EE45 y EE46 (Santa y Casma); EE39, EE40 y EE41 (Mariscal Ramón Castilla); EE56 y EE59 (Corredor Vial); EE58 y EE6o (Putumayo).
} 
fue decretado por el presidente Alejandro Toledo en mayo de 2003 a partir de las huelgas y protestas producidas en todo el país, iniciado por el Sindicato Único de Trabajadores de la Educación del Perú, al que se sumaron gremios de agricultores y trabajadores de la salud y el Poder Judicial (Wright, 2015: 66). Sin embargo, en su primera prórroga, este estado de emergencia es reconducido para cubrir algunas provincias de Junín, Ayacucho, Apurímac y Cusco - sin ninguna justificación - para enfrentar las actividades terroristas en dicha zona (Decreto Supremo 062-2003-PCM). Así, «la situación original de las protestas se utiliza luego para hacer frente a una "amenaza excepcional" desconocida, no especificada, dando paso a un régimen represivo de excepción por la puerta trasera» (Wright, 2015: 69; traducción propia). Este uso arbitrario e infundado del estado de emergencia, en que la medida inicialmente diseñada para afrontar una situación se transfiere a otra por completo distinta es, justamente, uno de los mayores riesgos de los poderes de emergencia (Wright, 2015: 69-70).

Por razones metodológicas, hemos elaborado cuatro categorías que intentan agrupar, a grandes rasgos, las razones que suelen motivar los estados de emergencia en el Perú: i) el terrorismo, ${ }^{18}$ ii) la conflictividad social, ${ }^{19}$ (iii) la criminalidad transfronteriza, ${ }^{20} \mathrm{y}$ iv) la seguridad ciudadana. ${ }^{21} \mathrm{Si}$ bien no pretendemos reducir cada situación a una determinada etiqueta, pues comprendemos sus particularidades y los problemas conexos que generan, resulta indispensable organizar las razones que justifican los estados de emergencia para estudiarlas con mayor profundidad. La tabla 1 refleja qué tan frecuente fue utilizada cada una de las categorías.

En el Perú posconflicto, el estado de emergencia por orden interno no se ha «desterrorizado»: sigue siendo utilizado, al igual que durante el conflicto armado, principal y permanentemente para enfrentar a las facciones terroristas que operan en

18. Para el presente artículo, entendemos terrorismo como los actos llevados a cabo posconflicto por los remanentes de Sendero Luminoso establecidos en el VRAEM, el Alto Huallaga y facciones relacionadas, que actualmente tienen fuertes vínculos con el narcotráfico. La finalidad de sus actos, para el Estado peruano, tienen por objetivo atentar contra el Estado de derecho y el orden constitucional.

19. Para los fines del presente estudio, entendemos conflictividad social como aquella situación identificada por el Ejecutivo como una amenaza para la seguridad y tranquilidad de las personas, el respeto a la autoridad pública o el resguardo de instalaciones públicas. Por lo general ha estado materializada en la forma de protestas sociales y huelgas de trabajadores.

20. Para los fines del presente estudio, entendemos criminalidad transfronteriza como aquella situación identificada por el Ejecutivo en el área amazónica cercana a la frontera donde operan organizaciones criminales dedicadas al narcotráfico, la trata de personas, la minería ilegal, el terrorismo y otras actividades ilícitas conexas. Si bien muchas de estas actividades ilícitas - en especial el terrorismo y el narcotráfico- han sido llevadas a cabo también en aquellas situaciones identificadas como terrorismo, entendemos que están centradas de forma específica en áreas fronterizas de la Amazonía.

21. Para los fines del presente estudio, entendemos seguridad ciudadana como aquella situación en la que el Ejecutivo identifica un grave problema de inseguridad generalizada en determinada área urbana caracterizada, principalmente por el crimen organizado y la delincuencia común. 
Tabla 1. Motivos que han justificado los estados de emergencia de orden interno en el Perú (2000-2018)

\begin{tabular}{|lll|}
\hline Motivo & Días de emergencia' & Estados de emergencia \\
\hline Terrorismo & 10.756 & 16 \\
\hline Conflictos sociales & 2.051 & 36 \\
Seguridad ciudadana & 675 & 4 \\
Criminalidad transfronteriza & 600 & 5 \\
\hline
\end{tabular}

1 El número de días es mayor al del período total porque existen, en determinados momentos, diversos estados de emergencia simultáneos en diferentes lugares de una misma región. Fuente: Elaboración propia.

áreas específicas del territorio nacional (Gurmendi, 2019: 149-152; Wright, 2015: 69). Por ello, como muestra la tabla 1, es el motivo que ha justificado, de lejos, la mayor cantidad de días bajo estado de emergencia.

En particular, hay dos áreas - donde han existido células activas de Sendero Luminoso- que han permanecido en un estado de emergencia casi permanente. Por un lado, la zona comprendida en el valle de los ríos Apurímac, Ene y Mantaro (VRAEM) ha permanecido en emergencia por casi dieciocho años (EE2, EE3, EE4, EE11, EE34 y EE47), es decir, por casi la totalidad del periodo estudiado. Por otro lado, la zona conocida como el Alto Huallaga estuvo en emergencia por cerca de ocho años (EE18, EE20, EE26, EE30 y EE33) hasta que llegó a su fin a mediados de 2015.

No obstante, las causas de los estados de emergencia por orden interno también se han diversificado. El terrorismo, si bien fue la categoría más utilizada, no fue la única que motivó declaraciones de emergencia en la etapa posconflicto. Por el contrario, de los 60 estados de emergencia, 35 de ellos tuvieron como justificación la conflictividad social. A pesar de que el número de días por terrorismo fue cinco veces mayor al de conflictividad social, estos últimos han sido utilizados con mayor frecuencia por un tiempo más reducido, que amerita el control de eventos particulares.

Diversos autores y organizaciones de la sociedad civil han dado cuenta del estado de emergencia como mecanismo institucional para reprimir y criminalizar la protesta social en el Perú. ${ }^{22} \mathrm{Si}$ bien en un inicio los conflictos sociales estuvieron representados sobre todo por protestas sociales y sindicales, con surgimiento del «boom extractivo» de recursos naturales (2001-2014) (Ávila, 2016), han estado especialmente ligados a tensiones socioambientales entre la población - usualmente indígena- de un determinado territorio, las empresas extractivas y el Estado peruano.

22. Véase Pérez (2012: 20-25), Wright (2013), Wright y Martí i Puig (2012); IDL y Justicia Viva (2012) y Coordinadora Nacional de Derechos Humanos (2017: 69-70). 
De hecho, el estado de emergencia ha sido utilizado en los principales episodios de protestas y manifestaciones de poblaciones indígenas en contra de los proyectos o actividades de extracción de recursos naturales. En 2009, el caso de Bagua (EE22 y EE25) sacudió al país. Diversas comunidades indígenas de la Amazonía peruana se movilizaron para protestar en contra de la emisión de un conjunto de normas que facilitaban los proyectos de extracción de recursos naturales. La situación de conflictividad social bajo estado de emergencia escaló hasta que, el 5 de junio de ese año, ocurrió un violento enfrentamiento con la policía en una zona conocida como «la Curva del Diablo» en la provincia de Bagua, que dejó más de 30 víctimas mortales, entre manifestantes y policías. Bagua marcó un antes y un después en la reivindicación de los territorios indígenas y llevó a que, tiempo después, se promulgara la ley de consulta previa (Wright, 2015: 68).

La emergencia también ha sido parte de la resistencia de las comunidades locales frente a grandes proyectos mineros. Por ejemplo, en 2012 el proyecto Conga en Cajamarca (EE36 y EE38) y Coroccohuayco, en la provincia de Espinar en Cusco (EE43). Más recientemente, el Estado peruano ha utilizado la emergencia para enfrentarse a la resistencia de la población local frente al proyecto Las Bambas en el corredor vial Apurímac-Cusco-Arequipa (2018), el cual llevaba más de 300 días en emergencia al finalizar el 2018 (EE56 y EE59).

Por su lado, la criminalidad en la frontera amazónica con Colombia y Brasil (zona norte de Loreto) también ha motivado la declaración de cinco estados de emergencia en ciertas ocasiones. Por último, la seguridad ciudadana justificó la adopción de un régimen de excepción sólo en los casos del Callao (EE31 y EE44) y las provincias de Santa y Casma en Áncash (EE45 y EE46).

\section{Las regiones en emergencia}

Por lo general, los estados de emergencia por orden interno han estado ubicados fuera de la región de Lima. Más allá de aquella única declaración de emergencia en todo el territorio nacional (EE2), durante el periodo materia de investigación se han declarado emergencias en 19 de las 24 regiones del Perú, además de la provincia constitucional del Callao. Aquellas cinco regiones que han sido (casi) inmunes a los estados de emergencia por orden interno son Ica, Moquegua, Pasco, Piura y Tumbes.

Las regiones listadas en la tabla 2 son, de acuerdo con los hallazgos de este estudio, aquéllas que han presentado mayores perturbaciones del orden interno durante el período estudiado. ${ }^{23} \mathrm{O}$, para ser más precisos, son aquellas regiones cuyas perturba-

23. En algunos casos, se modificaron las áreas geográficas comprendidas en la emergencia durante la vigencia de los estados de emergencia. La mayor parte de ellas se hicieron por medio de sus propias prórrogas, tanto para añadir o excluir ciertos territorios de aquel régimen de excepción. Sin embargo, en 
Tabla 2. Regiones con más días en estados de emergencia de orden interno (2000-2018)

\begin{tabular}{|lll|}
\hline Región & Días en emergencia $^{1}$ & Estados de emergencia \\
\hline Cusco & 7.860 & 17 \\
\hline Huancavelica & 5.808 & 8 \\
\hline Ayacucho & 5.756 & 8 \\
Junín & 5.730 & 7 \\
Huánuco & 3.388 & 7 \\
Ucayali & 2.902 & 8 \\
\hline San Martín & 2.848 & 6 \\
Apurímac & 1.740 & 12 \\
\hline
\end{tabular}

1 El número de días es mayor al del período total porque existen, en determinados momentos, diversos estados de emergencia simultáneos en diferentes lugares de una misma región. Asimismo, para la elaboración de dichas cifras no han sido tomados en cuenta los cambios territoriales en la vigencia de los estados de emergencia.

Fuente: Elaboración propia.

ciones al orden interno han sido enfrentadas por los Gobiernos con mayor frecuencia por medio de declaraciones de emergencia. Las cifras reflejan, entonces, el número total de días en los que distintas partes del territorio de una determinada región han estado bajo un régimen de emergencia.

La región que más ha sido objeto de estados de emergencia ha sido Cusco. En el período analizado, se declararon 17 estados de emergencia en distintas partes de su territorio, con una duración total de 7.860 días. La razón por la que Cusco ocupa el primer lugar es que, además de formar parte del área del VRAEM, también ha sido escenario de persistentes conflictos sociales en diferentes puntos de la región. Por un lado, cinco de los seis estados de emergencia más largos (EE4, EE11, EE34, EE36 y $\mathrm{EE} 47$ ), todos dedicados a enfrentar el terrorismo, incluyen o se limitan a la región del Cusco. Por el otro lado, esta región también ha albergado diversos conflictos sociales con una permanencia temporal relevante como, aquéllos en Echarate (EE22, EE25 y $\mathrm{EE}_{32}$ ) y Espinar (EE37, EE43 y EE51).

Todas las regiones listadas en la tabla 2 tienen una característica en común: forman parte de las áreas donde ha persistido —en distintos momentos e intensidadesla actividad de células terroristas.

cuatro oportunidades (EE2, EE4, EE5 y EE25) se emitió un decreto supremo adicional con el objetivo de ampliar el territorio comprendido en un estado de emergencia ya existente. En otra (EE55), no obstante, la opción del Gobierno fue declarar un nuevo estado de emergencia para los territorios adicionales, para que luego se incorporen en la emergencia original por medio de la siguiente prórroga. 
Si bien el análisis de las regiones sujetas a regímenes de emergencia nos entrega una fotografía de la distribución en el territorio nacional, un estudio más acucioso nos exige prestar más cuidado al espacio geográfico que han ocupado los estados de emergencia dentro de cada una de las regiones. Al respecto, los resultados de la presente investigación dan cuenta que los estados de emergencia han estado situados, en su gran mayoría, fuera de Lima y en zonas rurales (Wright, 2015: 72). A partir de ello, podemos afirmar que el estado de emergencia no ha operado de manera regular en las grandes ciudades del país, sino que, por el contrario, ha sido utilizado en forma consistente en las áreas menos urbanas para enfrentar el terrorismo, atender la conflictividad social y, en menor medida, la criminalidad transfronteriza.

\section{La suspensión de los derechos constitucionalmente permitidos}

Los estados de emergencia que versan sobre el orden interno, en su gran mayoría, han ordenado la suspensión del ejercicio de los cuatro derechos que permite la norma constitucional. No obstante, se registraron tres estados de emergencia (EE44, EE45 y EE46) - todos en materia de seguridad ciudadana- que sólo suspendieron los derechos a la libertad y seguridad personal y la inviolabilidad de domicilio. Éstos excluyeron la suspensión, por lo tanto, de los derechos a la libertad de reunión y de tránsito. Otro (EE27) sólo excluyó la libertad de reunión de la lista de derechos suspendidos. ${ }^{24}$

Resulta importante problematizar la forma en la cual los decretos supremos han redactado esta prerrogativa. Por un lado, todas las normas de emergencia hacen referencia a la suspensión y nunca a la restricción. De esta forma, siempre disponen el mayor grado de limitación en el ejercicio de los derechos constitucionales. No parece razonable, entonces, que se aplique un mismo nivel de restricción de derechos - peor aún, el máximo permitido constitucionalmente- para la diversidad de situaciones que han motivado las declaraciones de emergencia.

Por otro lado, además, el texto de las normas de emergencia estudiadas ordena la suspensión de los derechos y no - como manda la Constitución- de su ejercicio. Si bien este aspecto puede parecer irrelevante, da cuenta de la forma en la que el Ejecutivo entiende la restricción de derechos en un estado de emergencia: más como una derogación o inaplicación temporal y menos como una limitación del ejercicio de los derechos bajo los principios de razonabilidad y proporcionalidad. Todo esto, como

24. Existen declaraciones en los que se excluyen ciertos derechos suspendibles en alguna de sus prórrogas en particular y no en todo el estado de emergencia. De esta forma, el EE59 -en sus últimas dos prórrogas- delimitó los derechos suspendidos a la libertad de reunión y la inviolabilidad de domicilio. Asimismo, el EE1o - aunque sólo en una de sus prórrogas - excluyó la libertad de reunión de la lista de derechos suspendidos. El caso del EE12 es excepcional, ya que originalmente suspendía todos los derechos permitidos, pero ocho días después se publicó el Decreto Supremo 072-2006-PCM, que limitó la suspensión a los derechos a la libertad y seguridad personal. 
será precisado, tiene consecuencias directas en la responsabilidad internacional del Estado peruano, en virtud de los instrumentos internacionales de derechos humanos obligatorios para el Perú.

\section{La Policía Nacional del Perú, las Fuerzas Armadas y el uso de la fuerza}

Los estados de emergencia por orden interno en el Perú han sido liderados tanto por la Policía Nacional del Perú como las Fuerzas Armadas. En algunos casos, la Policía ha permanecido a cargo del control de orden interno - como establece la Constitución ante situaciones ordinarias ajenas a la emergencia- $y$, en otros, los instrumentos de emergencia han delegado el control del orden interno a las Fuerzas Armadas.

La tabla 3 muestra la distribución del control del orden interno entre la Policía y las Fuerzas Armadas, que han seguido los estados de emergencia en el Perú en el período estudiado. ${ }^{25}$ Por un lado, la Policía es quien ha tenido un ligero protagonismo en el control del orden interno en cuanto a días bajo este régimen de excepción. Sin embargo, en relación con el consolidado de estados de emergencia del anexo 1, la diferencia es abrumadora. Este fenómeno encuentra explicación en que las Fuerzas Armadas han asumido el control del orden interno en áreas donde existe una conflictividad permanente, mientras que la Policía usualmente ha sido designada en los estados de emergencia de menor duración.

Esto no significa que el control por parte de las Fuerzas Armadas haya estado dirigido en forma exclusiva a combatir el terrorismo, ni que el terrorismo haya sido enfrentado únicamente por las Fuerzas Armada. Por el contrario, tanto la Policía como las Fuerzas Armadas tuvieron el control del orden interno en las zonas declaradas en emergencia por terrorismo.

Asimismo, muchas de las situaciones de conflictividad social han sido atendidas por medio de la delegación del control del orden interno a las Fuerzas Armadas (EE1, $\mathrm{EE} 2, \mathrm{EE} 16, \mathrm{EE} 19, \mathrm{EE} 23, \mathrm{EE} 25, \mathrm{EE} 37$ ), lo cual resulta preocupante en el contexto de un patrón de criminalización de la protesta al que se hizo referencia antes.

La regla general ha sido que el control del orden interno permanezca en la misma institución a lo largo de la vigencia de los estados de emergencia. Sin embargo, hemos identificado tres escenarios cuyas prórrogas, en algún determinado momento, ordenaron el cambio de control del orden interno. Por ejemplo, el EE25 trasladó el control interno a las Fuerzas Armadas durante la vigencia del estado de emergencia. Por el contrario, el EE34 y el EE36 nacieron con las Fuerzas Armadas en el control y luego

25. Durante los primeros años del período, la autorización para que las FFAA asuman el control del orden interno tomaba la forma de una resolución suprema dictada en paralelo al estado de emergencia. Esto, como si el decreto supremo fuera insuficiente para hacerlo por sí mismo. Posteriormente, a partir de 2014, la habilitación para que la autoridad militar tome control del orden interno se incorporó en el propio decreto supremo que declara o prorroga el estado de emergencia. 
Tabla 3. Estados de emergencia según la institución encargada del control del orden interno (2000-2018)

\begin{tabular}{|lllll|}
\hline Institución & Días & & \multicolumn{2}{c|}{ Estados de emergencia } \\
\hline Policía Nacional del Perú & 7.160 & $50,9 \%$ & 49 & $77,8 \%$ \\
Fuerzas Armadas & 6.922 & $49,2 \%$ & 14 & $22,2 \%$ \\
\hline
\end{tabular}

1 La suma de los estados de emergencia con la Policía encargada del orden interno y aquellos otros con las Fuerzas Armadas a cargo supera los 60 identificados en el anexo 1, porque en tres oportunidades hubo un cambio durante la vigencia del estado de emergencia y fueron contabilizados en ambas categorías. Fuente: Elaboración propia.

retornó a manos de la Policía (Decreto Supremo o85-2015-PCM). Como es previsible, los Gobiernos no justificaron ni motivaron este importante cambio en la institución a cargo del orden interno.

Los decretos supremos estudiados históricamente no han hecho referencia a las normas que regulan el uso de la fuerza en el Perú. Ha sido por medio de la designación del control del orden interno que hace el Ejecutivo en el instrumento de emergencia que, implícitamente, se ha definido un nivel de fuerza a ser ejercido en una determinada situación. Recién a partir de agosto de 2016, los decretos empezaron a hacer referencia literal a las dos normas de derecho interno sobre el uso de la fuerza por parte de los agentes estatales encargados de custodiar el orden interno - Decreto Legislativo 1.186 (2015) o Decreto Legislativo 1.095 (2010) - que resultan aplicables (Decreto Supremo 071-2016-PCM).

\section{La práctica peruana de emergencia a la luz del derecho Internacional}

La suspensión del ejercicio de derechos debe ser entendida por medio de una lectura integrada de la Constitución y las obligaciones internacionales asumidas por el Estado, pues estas últimas también forman parte del ordenamiento jurídico nacional (Tribunal Constitucional, expediente 2730-2006-PA/TC).

Existe, pues, una pregunta inicial: ¿qué cuerpo normativo internacional se aplica durante los estados de emergencia? ¿el derecho internacional de derechos humanos o el derecho internacional humanitario? ¿Cuáles son las obligaciones internacionales que el Estado peruano debe cumplir en este contexto de emergencia?

La respuesta inicial es que el Perú, en virtud de los instrumentos internacionales de los que es parte, tiene el deber de cumplir con las obligaciones derivadas del derecho internacional de derechos humanos en todo momento, con independencia de si existe un estado de excepción o no. ${ }^{26}$ En ese sentido, las obligaciones de dere-

26. Caso Masacre de Santo Domingo con Colombia, Corte Interamericana de Derechos Humanos, párr. 21. 
chos humanos siguen siendo vinculantes para el Estado peruano durante el estado de emergencia.

Esto no significa que la declaración de emergencia no tenga un impacto en el estándar de derechos humanos que resulta exigible al Estado peruano en esta situación en particular. Los tratados de derechos humanos más importantes de los que el Perú es parte, como el Pacto Internacional de Derechos Civiles y Políticos (PIDCP) y la Convención Americana sobre Derechos Humanos (CADH) permiten la suspensión ${ }^{27}$ de determinadas obligaciones bajo contextos especiales como «situaciones excepcionales que pongan en peligro la vida de la nación» (PIDCP, artículo 4) o en casos de "guerra, peligro público o de otra emergencia que amenace la independencia o seguridad de Estado» (CADH, artículo 27) respectivamente. ${ }^{28}$

Sin embargo, los derechos que pueden ser suspendidos bajo los tratados de derecho internacional de derechos humanos no incluyen aquellos que se ven sobre todo afectados por el uso de la fuerza de la Policía y las Fuerzas Armadas: el derecho a la vida, a la integridad personal o a ciertas garantías judiciales. ¿Cuál es, entonces, el nivel de uso de la fuerza permitido por el derecho internacional de los derechos humanos durante el estado de emergencia?

Tanto la CIDH como la Corte IDH han señalado de forma reiterada que el uso de la fuerza por agentes de seguridad, aun en estados de emergencia, debe atenerse a criterios de legitimidad, necesidad, idoneidad y proporcionalidad. ${ }^{29}$ Naturalmente,

27. Seguimos utilizando suspensión (así, en itálicas) de las obligaciones internacionales porque este término tampoco implica la derogación temporal de dicho deber, sino - al igual que en el caso constitucional- de una «limitación extraordinaria» en el ejercicio de los derechos, siempre y cuando dichas limitaciones no atenten contra la sustancia de los derechos inherentes a la persona. Véase «Human rights in the administration of Justice: A manual on human rights for judges, prosecutors and lawyers», Oficina del Alto Comisionado para los Derechos Humanos, 2003, p. 814, disponible en https://bit. ly/2LXieUB; y Corte Interamericana de Derechos Humanos, Opinión Consultiva OC-8/87, «Habeas corpus bajo suspensión de garantías», párr. 18.

28. Tanto la CADH como el PIDCP señalan que los Estados parte que hagan uso de esta facultad tienen el deber de informar la aplicación de la cláusula de suspensión. A partir de ello, nos permitimos evaluar el cumplimiento de este deber del Estado peruano en el Sistema Interamericano de Protección de Derechos Humanos utilizando el archivo «Suspensión de garantías recientes en materia de tratados multilaterales», de Departamento de Derecho Internacional de la Organización de los Estados Americanos, disponible en https://bit.ly/3rjTqGA. Sin embargo, tras una lectura menos ociosa, se puede advertir que aquellos decretos supremos que son comunicados por el Estado peruano no comprenden el universo de normas que debió haber informado. Por ejemplo, en los años 2016 y 2017, sólo lograron comunicar 33 de las 48 normas que declaraban o prorrogaban estados de emergencia con suspensión de derechos.

29. Comisión Interamericana de Derechos Humanos, «Luis Jorge Valencia Hinojosa» (2014, párr. 181); «Informe sobre terrorismo y derechos humanos» (2002, párr. 87) e «Informe sobre seguridad ciudadana y derechos humanos» (2009, párr. 114). Corte IDH: caso Cruz Sánchez y Otros con Perú (2015, párr. 265); caso J. con Perú (2015, párr. 330) y caso Nadege Dorzema y otros con República Dominicana (2012, párr. 85). 
durante un estado de emergencia, estos parámetros comprenderán la excepcionalidad del contexto para permitir un mayor grado de restricción de derechos que en una situación de normalidad constitucional. De todas formas, el Estado peruano está sujeto a parámetros del derecho internacional de los derechos humanos que debe observar durante los estados de emergencia.

Entonces, ¿qué hay del derecho internacional humanitario? Estas normas se aplican en caso de conflicto armado (Pictet, 1990: 17-18), exista o no un estado de emergencia declarado a nivel doméstico. Esto no significa que en caso de conflicto armado el Estado se encuentra exonerado de sus obligaciones de derechos humanos. Tanto la Corte Internacional de Justicia como la Corte IDH coinciden en que, en contextos de conflicto armado, deberá operar la regla de lex specialis, según la cual las obligaciones estatales de derechos humanos serán interpretadas utilizando parámetros propios del derecho internacional humanitario. ${ }^{30}$ La doctrina de lex specialis no implica el desplazamiento de la norma general por la norma especial, sino un verdadero sistema de coaplicación. ${ }^{31}$ Así, los tribunales internacionales han sido enfáticos en que los tratados de derechos humanos siguen plenamente vigentes durante un conflicto armado, ${ }^{32}$ pero nutriéndose de las normas del derecho internacional humanitario. Hay, sin duda, un debate doctrinario en cuanto a los alcances y límites de esta coaplicación (Milanovic, 2016: 78-117).

A raíz de ello, surge naturalmente la siguiente interrogante: ¿existen, en los estados de emergencia estudiados, situaciones que califiquen como un conflicto armado interno de acuerdo con el derecho internacional? El Estado peruano ha guardado silencio al respecto. De todas formas, la determinación de un conflicto armado es un análisis fáctico de los requisitos de la existencia de un grupo armado organizado y la existencia de un nivel de violencia impuestos desde el derecho internacional, ${ }^{33}$ que no depende, pues, por el acuerdo de las partes en conflicto ni por la decisión de un órgano internacional (Tribunal Constitucional, expediente ooo22-2011-PI/TC, considerando 363).

No es el objetivo de este artículo evaluar la existencia fáctica de un conflicto armado durante el período estudiado. Sin embargo, sí resulta importante analizar qué estándares internacionales de uso de la fuerza y restricción de derechos humanos está siguiendo el Estado peruano en su práctica normalizada de declaración de emergencia.

30. Corte Internacional de Justicia, Opinión consultiva sobre la legalidad de la amenaza o del empleo de armas nucleares, párr. 25. Véase también «Opinión consultiva sobre las consecuencias jurídicas de la construcción de un muro en el territorio palestino ocupado», párrs. 106-113.

31. Caso Hermanas Serrano Cruz con El Salvador, Corte Interamericana de Derechos Humanos, párrs. $112,116$.

32. Caso Bámaca Velásquez con Guatemala, Corte Interamericana de Derechos Humanos, párr. 207.

33. Caso Fiscal con Dusko Tadic, Tribunal Penal Internacional para la antigua Yugoslavia, párr. 70. 
En el Perú, las normas que regulan el uso de la fuerza por agentes estatales siguen los estándares propuestos desde el derecho internacional. Mientras que el Decreto Legislativo 1.186 (2015) incorpora los parámetros del derecho internacional de los derechos humanos cuando el control del orden interno permanece en la Policía, ${ }^{34}$ el Decreto Legislativo 1.095 (2010) contiene las normas de derecho internacional humanitario en aquellos casos que el control del orden interno es delegado a las Fuerzas Armadas. ${ }^{35}$

En ese sentido, cuando los decretos supremos han trasladado el control del orden interno a las Fuerzas Armadas, el Estado peruano ha autorizado de forma implícita que los agentes militares utilicen un nivel de la fuerza dedicado exclusivamente para conflictos armados. Asimismo, desde 2016 que dichas normas afirman que los remanentes terroristas configuran un grupo $\operatorname{armado}^{36}$ y señalan en forma explícita que resulta aplicable el derecho internacional humanitario (Decreto Supremo o76-2016PCM). De esta forma, durante el período posconflicto, el Estado peruano ha venido aplicando estándares de uso de la fuerza de un conflicto armado en casi la mitad de los días en situación de emergencia (tabla 3).

Esta situación resulta alarmante, pues, como este estudio ha verificado, la declaración de emergencia en el Perú está normalizada sin mayor justificación sobre el grado de restricción de derechos adecuados para cada contexto. Más preocupante aún, este estándar de uso de la fuerza para conflictos armados no ha sido exclusivo de las situaciones identificadas como «terroristas», sino también en contextos de conflictividad social como protestas ciudadanas (véase supra).

Si bien el Estado peruano ha venido - tanto implícita como explícitamente-aplicando estándares de derecho internacional humanitario diseñados para conflictos armados, la doctrina más autorizada en la materia coincide en señalar que, con los elementos de juicio disponibles, la situación de «terrorismo» en el VRAEM duran-

34. Al respecto, advertimos con mucha preocupación que en marzo de 2020 se promulgó la Ley 31.012, Ley de Protección Policial, que derogó el artículo del Decreto Legislativo 1.186, que contenía el principio de proporcionalidad en el uso de la fuerza por parte de la Policía. Este cambio legislativo, sin embargo, no debería tener efectos prácticos, en tanto el principio de proporcionalidad es una norma de derecho internacional de los derechos humanos que los operadores jurídicos en el Perú deben acatar.

35. El Decreto Legislativo 1.095 (2010) establece que cuando el control del orden interno permanece en la Policía resulta aplicable el derecho internacional de los derechos humanos, mientras que cuando dicho control es trasladado a las Fuerzas Armadas, se sujetan a las normas tanto del derecho internacional humanitario como del derecho internacional de los derechos humanos.

36. Desde el Decreto Supremo 017-2016-PCM. Si bien el término que utilizó la norma fue «grupo hostil», el Tribunal Constitucional en 2015 señaló que este término debía de ser interpretado de forma equivalente al grupo armado de acuerdo con el artículo 1.1 del Protocolo Adicional II a los Convenios de Ginebra y el artículo 3 común (Tribunal Constitucional, expediente ooo22-2011-PI/TC, considerando resolutivo 2.6). 
te el período estudiado no cumple con los estándares mínimos para configurar un conflicto armado interno de acuerdo con el derecho internacional (Gurmendi, 2019: 149-152). ${ }^{37}$ Por el contrario, el terrorismo posconflicto parecería asimilarse más a los disturbios internos en que existen actos de violencia esporádica que involucran a diversos actores sociales relativamente organizados en revueltas temporales en una situación general de paz social (Salmón, 2016: 170).

$\mathrm{Al}$ respecto, el Protocolo Adicional 2 es claro: las normas de derecho internacional humanitario no se aplicarán en casos «de tensiones internas y de disturbios interiores, tales como los motines, los actos esporádicos y aislados de violencia y otros actos análogos, que no son conflictos armados» (artículo 1.2). Sobre ello, el Tribunal Constitucional afirmó que los casos de disturbios sociales y tensiones internas que no suponen la existencia de un conflicto armado se rigen por el derecho internacional de los derechos humanos; sin embargo, también agregó que la doctrina y jurisprudencia internacional han admitido que, en este contexto, el derecho internacional de los derechos humanos pueda ser complementado con disposiciones fundamentales del derecho internacional humanitario que promuevan el principio de humanidad (Tribunal Constitucional, expediente oooz2-2011-PI/TC, considerandos $371 .^{\circ}$ y $\left.372 .^{\circ}\right)$. De todas formas, los grupos que participen de los disturbios sociales y tensiones internas «no podrán ser considerados como grupo hostil que merezca un enfrentamiento militar por parte del Estado» (Tribunal Constitucional, expediente ooo22-2011-PI/TC, considerando $373 .{ }^{\circ}$ ).

Por lo tanto, el Estado peruano, al no fundamentar los motivos que lo llevan a habilitar estándares de uso de la fuerza propios del derecho internacional humanitario, está comprometiendo seriamente su responsabilidad internacional en situaciones que parecerían no calificar como un conflicto armado no internacional.

\section{Reflexiones finales}

La presente investigación muestra que el estado de emergencia en el Perú democrático posconflicto (2000-2018) sigue normalizado. En el período estudiado encontramos 742 normas de emergencia, de las cuales 272 fueron por orden interno, en que se suspende el ejercicio de ciertos derechos. Estas últimas, organizadas en los 60 estados de emergencia del anexo 1, suman 14.082 días en que diversas localidades del país estuvieron en emergencia. Las áreas donde operan remanentes terroristas, por ejemplo, estuvieron en casi permanente emergencia desde el inicio del periodo.

Esta situación ha logrado institucionalizarse en el aparato estatal a partir de la falta de un procedimiento integral y transversal para la propuesta, el debate, el mo-

37. Véase también Elizabeth Salmón, «¿Existe un conflicto armado en el VRAEM?», El Comercio, 26 de julio de 2018, disponible en https://bit.ly/3mC3Uoh. 
nitoreo y la evaluación de las normas que declaran o prorrogan los regímenes de emergencia por orden interno. El Perú, entonces, no cuenta con un sistema integrado que permita identificar situaciones de riesgo y evaluar la necesidad de declarar un estado de emergencia por orden interno en determinada parte del territorio nacional. Tampoco existen fórmulas reales y efectivas de contrapeso o revisión por parte de otros poderes del Estado. De esta forma, los Gobiernos de turno han establecido y perpetuado estados de emergencia sin hacer un análisis particular de la situación que desean enfrentar y sin diseñar una política pública alrededor de ella.

Este contexto de normalización de la emergencia es en particular preocupante, porque el Ejecutivo no ha sido consciente de las consecuencias jurídicas que conlleva la suspensión - casi por default- del ejercicio de los derechos permitidos constitucionalmente que ha dispuesto en mayoría de casos. Más aún, cuando aquella suspensión estuvo acompañada, en casi la mitad de los días de emergencia, de la delegación del control de orden interno a las Fuerzas Armadas tanto para situaciones de terrorismo como de conflictividad social. En estos últimos, el Estado peruano ha venido aplicando estándares de derecho internacional humanitario - implícitamente y, desde 2016, también de forma explícita-, a pesar de la ausencia de elementos de juicio que permitan argumentar la existencia de un conflicto armado no internacional de acuerdo con los criterios formulados desde el derecho internacional.

En el actual contexto internacional de lucha contra la pandemia del covid-19, el Estado peruano ha decidido decretar un estado de emergencia a nivel nacional para enfrentar los desafíos que implican estas extraordinarias circunstancias. Esta es la primera vez que en el Perú se decreta un estado de emergencia en todo el territorio nacional desde que en 2003 se declaró en emergencia todo el país, pero pocos días después se redujo a un grupo de provincias específicas (EE2). Además, la motivación de este estado de emergencia nacional rompe con los típicos usos que esta investigación identificó se le ha dado al estado de emergencia en el Perú posconflicto como, por ejemplo, el terrorismo, la conflictividad social, el tráfico ilícito de drogas o la seguridad ciudadana. A partir de ello, advertimos que es probable que los riesgos señalados a lo largo del artículo en el uso de los estados de emergencia en el Perú también se vean reflejados en este nuevo contexto y que surjan nuevos desafíos en la implementación de esta medida a nivel nacional. Sólo el tiempo permitirá evaluar el desempeño del Estado peruano al aplicar esta medida de excepción en tiempos de covid-19.

Si bien éste es sólo un análisis preliminar de lo todo lo que puede ofrecer el estudio de las normas de excepción, los hallazgos de la presente investigación nos invitan a repensar la institución de estado de emergencia a partir de su aplicación en el Perú. Por ello, las cláusulas tradicionales de excepción - como el artículo 137 de nuestra Constitución - no han sido adecuadas para atender las distintas amenazas constitucionales bajo un rígido binomio cuya utilidad fue diseñada en contextos que no se acomodan más a la realidad actual. 


\section{Reconocimiento}

Una versión preliminar de este estudio fue presentada en la conferencia Nuevos Retos en Materia de Seguridad: Crimen Organizado y Conflicto Urbano en el Continente Americano, organizada por la Facultad de Derecho de la Universidad del Pacífico entre el 24 y el 26 de octubre de 2018.

\section{Referencias}

AbAD, Samuel (2004). "Retos jurídicos del informe de la CVR: La necesaria garantía del derecho a la verdad». Derecho PUCP, 57: 41-58. DOI: 10.18800/ derechopucp.200401.002.

ACKerman, Bruce (2007). Antes de que nos ataquen de nuevo: La defensa de las libertades en tiempos de terrorismo. Barcelona: Península.

Ávila, Gustavo (2016). Los efectos del boom de las industrias extractivas en los indicadores sociales. Lima: Natural Resource Governance Institute. Disponible en https://bit.ly/2LTBMJn.

Calveiro, Pilar (2008). "Acerca de la difícil relación entre violencia y resistencia». En Margarita López, Nicolás Iñigo y Pilar Calveiro (editores), Luchas contrahegemónicas y cambios políticos recientes de América Latina (pp. 23-46). Buenos Aires: Clacso.

Chirinos Soto, Enrique (1997). Constitución de 1993: Lectura y comentario. Lima: Nerman.

CVR, Comisión de la Verdad y Reconciliación (2003). Informe final (Perú: 1980200o). Lima.

Coordinadora Nacional de Derechos Humanos (2017). Criminalización de la protesta y la situación de los defensores y defensoras de los derechos humanos. Lima: Coordinadora Nacional de Derechos Humanos. Disponible en https://bit. ly/34wcbwM.

Defensoría del Pueblo (2003). Restricción de derechos en democracia: Supervisando el estado de emergencia. Lima: Defensoría del Pueblo. Disponible en https://bit. ly/34Ahs6h.

Dyzenhaus, David (2002). «The permanence of the temporary: Can emergency powers be normalized?». En Ronald Daniels, Patrick Macklem y Kent Roach (editores), The security of freedom: Essay on Canada's anti-terrorism bill (pp. 21-37). Toronto: University of Toronto Press.

Grandez, Agustín (2012). «¿Estamos frente a una desnaturalización del estado de emergencia?». Actualidad Jurídica, 222: 205-211.

Gurmendi, Alonso (2019). Conflicto armado en el Perú: La época del terrorismo bajo el derecho internacional. Lima: Fondo Editorial de la Universidad del Pacífico. 
IDL, Instituto de Defensa Legal y Justicia Viva (2012). La criminalización de las protestas sociales durante el primer año de Gobierno de Ollanta Humala: De la gran transformación a la mano dura. Lima. Disponible en https://bit.ly/3rlePim.

Milanovic, Marko (2016). «The lost origins of lex specialis». En Jens David Ohlin (editor), Theoretical boundaries of armed conflict and human rights (pp. 78-117). Cambridge: Cambridge University Press.

PÉrez, Mar (2012). «Conflictividad social y vulneración de derechos». En Coordinadora Nacional de Derechos Humanos, Informe anual 2011- 2012: Un año del Gobierno de Ollanta Humala (pp. 17-25). Disponible en https://bit.ly/3rfYjAh.

Pictet, Jean (1990). «El derecho internacional humanitario: Definición». En Las dimensiones internacionales del derecho humanitario. Madrid: Tecnos.

SALDAÑA, José y Jorge Portocarrero (2017). «La violencia de las leyes: El uso de la fuerza y la criminalización de protestas socioambientales en el Perú». Derecho PUCP, 79: 311-352. DOI: 10.1880o/derechopucp.201702.013.

SALMón, Elizabeth (2016). Introducción al derecho internacional humanitario. Lima: Pontificia Universidad Católica del Perú y Comité Internacional de la Cruz Roja.

Siles, Abraham (2015). «La emergencia... En el corazón del constitucionalismo peruano: Paradojas, aporías y normalización». Themis, 67: 73-84. Disponible en https://bit.ly/2LZ84mr.

-. (2017). «Problemática constitucional del estado de emergencia en Perú: Algunas cuestiones fundamentales». Estudios Constitucionales, 15 (2): 123-166. DOI: 10.4067/So718-52002017000200123.

Wright, Claire (2013). «Perú: El estado de emergencia como mecanismo de represión de la protesta indígena en el contexto de conflictos sobre recursos naturales». En Salvador Martí i Puig, Claire Wright, José Aylwin y Nancy Yáñez (editores), Entre el desarrollo y el buen vivir: Recursos naturales y conflictos en los territorios indígenas (pp. 265-292). Madrid: Ediciones la Catarata.

-. (2015). Emergency politics in the third wave of democracy: A study of regimes of exception in Bolivia, Ecuador, and Peru. Londres: Lewington Books.

WRIGHT, Claire y Salvador Martí i Puig (2012). «Conflicts over natural resources and activation of indigenous identity in Cusco, Peru». Latin American And Caribbean Ethnic Studies, 7 (3): 249-274. DOI: 10.1080/17442222.2012.723905.

\section{Sobre los autores}

Andrea Tafur Sialer es bachiller en Derecho por la Universidad del Pacífico, Perú, con estudios de especialidad en la Academia de Derecho Internacional de La Haya. Su correo electrónico es ap.tafurs@alum.up.edu.pe. (D) https://orcid. org/0000-0002-3191-7810. 
Diego Quesada Nicoli es bachiller en Derecho por la Universidad del Pacífico, Perú, con estudios de especialidad en la Academia de Derecho Internacional de La Haya. Asistente de investigación en el Centro de Investigación de la Universidad del Pacífico. Su correo electrónico es d.quesadanicoli@alum.up.edu.pe. (D) https://orcid. org/0000-0002-2519-9082.

Anexo. Estados de emergencia en el Perú (2000-2018)

\begin{tabular}{|c|c|c|c|c|c|c|c|c|}
\hline EE & Provincias & Regiones & $\begin{array}{l}\text { Fecha } \\
\text { de inicio }\end{array}$ & $\begin{array}{l}\text { Fecha } \\
\text { de fin }\end{array}$ & Prórrogas & Días & Control & Motivo \\
\hline 1 & & Arequipa & 17/6/2002 & $22 / 6 / 2002$ & 0 & 61 & FFAA & Conflictividad social \\
\hline 2 & & Nacional $\left.\right|^{2}$ & 29/5/2003 & $24 / 8 / 2003^{3}$ & 2 & 90 & FFAA $^{4}$ & $\begin{array}{l}\text { Conflictividad social/ } \\
\text { Terrorismo }{ }^{5}\end{array}$ \\
\hline & Andahuaylas y Chincheros & Apurímac & \multirow{5}{*}{ 29/8/2003 } & \multirow{5}{*}{$25 / 11 / 2003^{6}$} & \multirow{5}{*}{1} & \multirow{5}{*}{90} & \multirow{5}{*}{ FFAA" } & \multirow{5}{*}{ Terrorismo } \\
\hline & Huanta y La Mar & Ayacucho & & & & & & \\
\hline & Tayacaja & Huancavelica & & & & & & \\
\hline 3 & La Convención & Cusco & & & & & & \\
\hline & $\begin{array}{l}\text { Satipo, Concepción (Andamarca) } \\
\text { y Huancayo (Santo Domingo de } \\
\text { Acobamba) }\end{array}$ & Junín & & & & & & \\
\hline \multirow{5}{*}{4} & Andahuaylas y Chincheros ${ }^{7}$ & Apurímac & \multirow{5}{*}{ 28/11/2003 } & \multirow{5}{*}{ 14/5/20068 } & \multirow{5}{*}{14} & \multirow{5}{*}{900} & \multirow{5}{*}{ FFAA } & \multirow{5}{*}{ Terrorismo } \\
\hline & Huanta y La Mar & Ayacucho & & & & & & \\
\hline & Tayacaja & Huancavelica & & & & & & \\
\hline & La Convención & Cusco & & & & & & \\
\hline & $\begin{array}{l}\text { Satipo, Concepción (Andamarca) } \\
\text { y Huancayo (Santo Domingo de } \\
\text { Acobamba) }\end{array}$ & Junín & & & & & & \\
\hline 5 & $\begin{array}{l}\text { Carabaya (San Gabán) y Melgar } \\
\text { (Antauta) }^{9}\end{array}$ & Puno & 19/10/2004 & 17/11/2004 & 0 & 30 & PNP & Conflictividad social \\
\hline 6 & Alto Amazonas & Loreto & 6/11/2004 & $5 / 12 / 2004$ & 0 & 30 & PNP & Conflictividad social \\
\hline 7 & $\begin{array}{l}\text { Carabaya (San Gabán, Ollachea y } \\
\text { Ayapata) y Melgar (Antauta) }\end{array}$ & Puno & $23 / 11 / 2004$ & $27 / 2 / 2005^{10}$ & 1 & 98 & PNP & Conflictividad social \\
\hline 8 & & Apurímac & 2/1/2005 & $31 / 1 / 2005$ & 0 & 30 & PNP & Terrorismo \\
\hline 9 & Andahuaylas y Chincheros & Apurímac & $4 / 4 / 2005$ & $3 / 5 / 2005$ & 0 & 30 & PNP & Terrorismo \\
\hline 10 & $\begin{array}{l}\text { Marañón, Huacaybamba, Leoncio } \\
\text { Prado y Huamalíes }\end{array}$ & Huánuco & $23 / 12 / 2005$ & $16 / 6 / 2007^{11}$ & 8 & 540 & PNP & Terrorismo \\
\hline \multirow{4}{*}{11} & Huanta y La Mar & Ayacucho & \multirow{4}{*}{$30 / 5 / 2006$} & \multirow{4}{*}{$30 / 10 / 2011$} & \multirow{4}{*}{32} & \multirow{4}{*}{1.980} & \multirow{4}{*}{ FFAA } & \multirow{4}{*}{ Terrorismo } \\
\hline & Tayacaja & Huancavelica & & & & & & \\
\hline & $\begin{array}{l}\text { La Concepción (Kimbiri, Pichari y } \\
\text { Vilcabamba) }^{12}\end{array}$ & Cusco & & & & & & \\
\hline & $\begin{array}{l}\text { Satipo, Concepción (Andamarca y } \\
\text { Comas) y Huancayo (Santo Domin- } \\
\text { go de Acobamba y Pariahuanca)ww }\end{array}$ & Junín & & & & & & \\
\hline 12 & Chiclayo & Lambayeque & 13/10/2006 & $31 / 12 / 2006$ & 1 & 80 & PNP & Conflictividad social \\
\hline 13 & Abancay & Apurímac & 7/12/2006 & 5/1/2007 & 0 & 30 & PNP & Conflictividad social \\
\hline 14 & Islay (Cocachacra) & Arequipa & 3/3/2007 & $15 / 4 / 2007^{14}$ & 1 & 45 & PNP & Conflictividad social \\
\hline 15 & Lima (Santa Anita) & Lima & 26/5/2007 & 1/6/2007 & 0 & 7 & PNP & Conflictividad social \\
\hline
\end{tabular}




\begin{tabular}{|c|c|c|c|c|c|c|c|c|}
\hline EE & Provincias & Regiones & $\begin{array}{l}\text { Fecha } \\
\text { de inicio }\end{array}$ & $\begin{array}{l}\text { Fecha } \\
\text { de fin }\end{array}$ & Prórrogas & Días & Control & Motivo \\
\hline 16 & Ucayali (Sarayacu) & Loreto & $30 / 6 / 2007$ & 6/7/2007 & 0 & 7 & FFAA & Conflictividad social \\
\hline 17 & Coronel Portillo & Ucayali & $30 / 6 / 2007$ & $9 / 7 / 2007$ & 0 & 1015 & PNP & Conflictividad social \\
\hline \multirow{3}{*}{18} & $\begin{array}{l}\text { Marañón, Huacaybamba, Huama- } \\
\text { líes y Leoncio Prado }{ }^{16}\end{array}$ & Huánuco & \multirow{3}{*}{$2 / 7 / 2007$} & \multirow{3}{*}{ 28/12/2007 } & \multirow{3}{*}{2} & \multirow{3}{*}{180} & \multirow{3}{*}{ PNP } & \multirow{3}{*}{ Terrorismo } \\
\hline & Tocache & San Martín & & & & & & \\
\hline & Padre Abad & Ucayali & & & & & & \\
\hline \multirow{3}{*}{19} & Huaura, Huaral y Barranca & Lima & \multirow{3}{*}{$19 / 2 / 2008$} & \multirow{3}{*}{$25 / 2 / 2008$} & \multirow{3}{*}{0} & \multirow{3}{*}{7} & \multirow{3}{*}{ FFAA } & \multirow{3}{*}{ Conflictividad social } \\
\hline & Huarmey, Casma y Santa & Áncash & & & & & & \\
\hline & Virú & La Libertad & & & & & & \\
\hline \multirow{3}{*}{20} & $\begin{array}{l}\text { Marañón (Cholón), Huamalíes } \\
\text { (Monzón) y Leoncio Prado }\end{array}$ & Huánuco & \multirow{3}{*}{$7 / 3 / 2008$} & \multirow{3}{*}{$29 / 8 / 2009^{17}$} & \multirow{3}{*}{8} & \multirow{3}{*}{540} & \multirow{3}{*}{ PNP } & \multirow{3}{*}{ Terrorismo } \\
\hline & Tocache & San Martín & & & & & & \\
\hline & Padre Abad & Ucayali & & & & & & \\
\hline 21 & & Madre de Dios & $14 / 7 / 2008$ & $11 / 9 / 2008$ & 0 & 60 & PNP & Conflictividad social \\
\hline \multirow{3}{*}{22} & Bagua y Utcubamba & Amazonas & \multirow{3}{*}{$19 / 8 / 2008$} & \multirow{3}{*}{$28 / 8 / 2008$} & \multirow{3}{*}{0} & & & \\
\hline & Datem del Marañón & Loreto & & & & 1018 & PNP & Conflictividad social \\
\hline & La Convención (Echarate) & Cusco & & & & & & \\
\hline 23 & $\begin{array}{l}\text { Tacna, Jorge Basadre, Candarave } \\
\text { y Tarata }\end{array}$ & Tacna & $5 / 11 / 2008$ & $4 / 12 / 2008$ & 0 & 30 & FFAA & Conflictividad social \\
\hline 24 & $\begin{array}{l}\text { Huamanga (Chiara, Vinchos, Acocro } \\
\text { y Acos Vinchos) }\end{array}$ & Ayacucho & $1 / 1 / 2009$ & $5 / 2 / 2009$ & 0 & 3619 & PNP & Conflictividad social \\
\hline & La Convención (Echarate y Kimbiri) & Cusco $^{20}$ & & & & & & \\
\hline & Atalaya (Sepahua) & Ucayali & & & & & & \\
\hline 25 & $\begin{array}{l}\text { Maynas (Napo) y Datem del Ma- } \\
\text { rañón (Andoas, Pastaza, Morona y } \\
\text { Manseriche) }\end{array}$ & Loreto & $10 / 5 / 2009$ & $22 / 6 / 2009$ & 0 & 4421 & $\begin{array}{l}\text { PNP/ } \\
\text { FFAA }^{22}\end{array}$ & Conflictividad social \\
\hline & Bagua (Imaza) & Amazonas & & & & & & \\
\hline & $\begin{array}{l}\text { Marañón (Cholón), Huamalíes } \\
\text { (Monzón) y Leoncio Prado }\end{array}$ & Huánuco & & & & & & \\
\hline 26 & Tocache & San Martín & $11 / 9 / 2009$ & $8 / 5 / 2010$ & 3 & 240 & PNP & lerrorismo \\
\hline & Padre Abad & Ucayali & & & & & & \\
\hline 27 & Abancay & Apurímac & $2 / 12 / 2009$ & $30 / 1 / 2010$ & 0 & 60 & PNP & Conflictividad social \\
\hline 28 & Red Vial Centro & Junín & 20/1/2010 & $18 / 2 / 2010$ & 0 & 30 & PNP & Conflictividad social \\
\hline 28 & kea vial centro & Lima & $20 / 1 / 2010$ & $18 / 2 / 2010$ & 0 & 30 & PINP & Comilictiviada social \\
\hline 29 & $\begin{array}{l}\text { Nazca, Palpa y San Juan de } \\
\text { Marcona }\end{array}$ & Ica & $01 / 4 / 2010$ & $30 / 5 / 2010$ & 0 & 60 & PNP & Conflictividad social \\
\hline 29 & Tambopata y Manu & Madre de Dios & $01 / 4 / 2010$ & $30 / 5 / 2010$ & 0 & 60 & PINP & Contlictividad social \\
\hline & Caravelí y Camaná & Arequipa & & & & & & \\
\hline 30 & $\begin{array}{l}\text { Marañón (Cholón), Huamalíes } \\
\text { (Monzón) y Leoncio Prado }\end{array}$ & Huánuco & $15 / 5 / 2010$ & $6 / 9 / 20123$ & 7 & & & \\
\hline 30 & Tocache & San Martín & $15 / 5 / 2010$ & $6 / 9 / 2011^{25}$ & 7 & 480 & PNP & lerrorismo \\
\hline & Padre Abad & Ucayali & & & & & & \\
\hline 31 & Callao & Callao & $19 / 5 / 2010$ & $17 / 7 / 2010$ & 0 & 60 & PNP & $\begin{array}{l}\text { Seguridad } \\
\text { ciudadana }\end{array}$ \\
\hline 32 & La Convención (Echarate) & Cusco & $1 / 8 / 2010$ & $12 / 8 / 2010$ & 0 & 1224 & PNP & Conflictividad social \\
\hline 33 & $\begin{array}{l}\text { Marañón (Cholón), Huamalíes } \\
\text { (Monzón) y Leoncio Prado }\end{array}$ & Huánuco & & & & & & \\
\hline 33 & Tocache & San Martín & $13 / 9 / 2011$ & $23 / 6 / 201525$ & 22 & 1.380 & PNP & lerrorismo \\
\hline & Padre Abad & Ucayali & & & & & & \\
\hline
\end{tabular}




\begin{tabular}{|c|c|c|c|c|c|c|c|c|}
\hline EE & Provincias & Regiones & $\begin{array}{l}\text { Fecha } \\
\text { de inicio }\end{array}$ & $\begin{array}{l}\text { Fecha } \\
\text { de fin }\end{array}$ & Prórrogas & Días & Control & Motivo \\
\hline \multirow{4}{*}{34} & Huanta y La Mar & Ayacucho & \multirow{4}{*}{ 7/11/2011 } & \multirow{4}{*}{$10 / 10 / 2016$} & \multirow{4}{*}{30} & \multirow{4}{*}{1.800} & \multirow{4}{*}{$\begin{array}{l}\text { FFAA/ } \\
\text { PNP26 }^{26}\end{array}$} & \multirow{4}{*}{ Terrorismo } \\
\hline & Tayacaja & Huancavelica & & & & & & \\
\hline & $\begin{array}{l}\text { La Concepción (Kimbiri, Pichari y } \\
\text { Vilcabamba) }\end{array}$ & Cusco & & & & & & \\
\hline & $\begin{array}{l}\text { Satipo, Concepción (Andamarca y } \\
\text { Comas) y Huancayo (Santo Domin- } \\
\text { go de Acobamba y Pariahuanca) }\end{array}$ & Junín & & & & & & \\
\hline 35 & $\begin{array}{l}\text { Cajamarca, Celendín, Hualgayocy } \\
\text { Contumazá }\end{array}$ & Cajamarca & $5 / 12 / 2011$ & $15 / 12 / 2011$ & 0 & 1127 & PNP & Conflictividad social \\
\hline 36 & La Convención (Echarate) & Cusco & $10 / 4 / 2012$ & $11 / 10 / 2016$ & 26 & $1.644^{28}$ & $\begin{array}{l}\text { FFAA/ } \\
\text { PNP29 }\end{array}$ & Terrorismo \\
\hline 37 & Espinar & Cusco & $29 / 5 / 2012$ & $27 / 6 / 2012$ & 0 & 30 & FFAA & Conflictividad social \\
\hline 38 & Cajamarca, Celendín y Hualgayoc & Cajamarca & 4/7/2012 & $1 / 9 / 2012$ & 1 & 60 & PNP & Conflictividad social \\
\hline 39 & $\begin{array}{l}\text { Mariscal Ramón Castilla (Ramón } \\
\text { Castilla y Yavarí) }\end{array}$ & Loreto & $12 / 09 / 2014$ & $10 / 11 / 2014$ & 0 & 60 & PNP & $\begin{array}{l}\text { Criminalidad } \\
\text { transfronteriza }\end{array}$ \\
\hline 40 & $\begin{array}{l}\text { Mariscal Ramón Castilla (Ramón } \\
\text { Castilla y Yavarí) }\end{array}$ & Loreto & 20/11/2014 & 19/3/2015 & 1 & 120 & PNP & $\begin{array}{l}\text { Criminalidad } \\
\text { transfronteriza }\end{array}$ \\
\hline 41 & $\begin{array}{l}\text { Mariscal Ramón Castilla (Ramón } \\
\text { Castilla y Yavarí) }\end{array}$ & Loreto & $21 / 3 / 2015$ & $14 / 1 / 2016$ & 4 & 300 & PNP & $\begin{array}{l}\text { Criminalidad } \\
\text { transfronteriza }\end{array}$ \\
\hline 42 & $\begin{array}{l}\text { Islay (Matarani, Mollendo, Mejía, } \\
\text { Punta de Bombón, Dean Valdivia, } \\
\text { La Curva, El Arenal, Cocachacra y } \\
\text { Valle del Tambo) }\end{array}$ & Arequipa & $22 / 5 / 2015$ & 21/7/2015 & 0 & 60 & PNP & Conflictividad social \\
\hline \multirow[t]{2}{*}{43} & $\begin{array}{l}\text { Cotabambas, Grau, Andahuaylas y } \\
\text { Chincheros }\end{array}$ & Apurímac & \multirow[t]{2}{*}{$30 / 9 / 2015$} & \multirow[t]{2}{*}{$29 / 10 / 2015$} & \multirow[t]{2}{*}{0} & \multirow[t]{2}{*}{30} & \multirow[t]{2}{*}{ PNP } & \multirow[t]{2}{*}{ Conflictividad social } \\
\hline & Chumbivilcas y Espinar & Cusco & & & & & & \\
\hline 44 & Callao & Callao & $4 / 12 / 2015$ & $13 / 10 / 2016$ & 6 & 315 & PNP & $\begin{array}{l}\text { Seguridad } \\
\text { ciudadana }\end{array}$ \\
\hline 45 & Santa y Casma & Áncash & $24 / 12 / 2015$ & 6/2/2016 & 0 & 45 & PNP & $\begin{array}{l}\text { Seguridad } \\
\text { ciudadana }\end{array}$ \\
\hline 46 & Santa y Casma & Áncash & $10 / 2 / 2016$ & $21 / 10 / 2016$ & 5 & 255 & PNP & $\begin{array}{l}\text { Seguridad } \\
\text { ciudadana }\end{array}$ \\
\hline \multirow{4}{*}{47} & Huanta y La Mar30 & Ayacucho & \multirow{4}{*}{$11 / 10 / 2016$} & \multirow{4}{*}{ 28/1/2019 } & \multirow{4}{*}{13} & \multirow{4}{*}{840} & \multirow{4}{*}{ FFAA } & \multirow{4}{*}{ Terrorismo } \\
\hline & Tayacaja & Huancavelica & & & & & & \\
\hline & La Convención & Cusco & & & & & & \\
\hline & Satipo, Concepción y Huancayo & Junín & & & & & & \\
\hline 48 & San Román & Puno & $30 / 11 / 2016$ & $29 / 12 / 2016$ & 0 & 30 & PNP & Conflictividad social \\
\hline 49 & Chumbivilcas & Cusco & 21/12/2016 & 19/1/2017 & 0 & 30 & PNP & Conflictividad social \\
\hline 50 & Cotabambas & Apurímac & $11 / 2 / 2017$ & $12 / 3 / 2017$ & 0 & 30 & PNP & Conflictividad social \\
\hline 51 & Espinar (Coporaque) & Cusco & $22 / 2 / 2017$ & $23 / 3 / 2017$ & 0 & 30 & PNP & Conflictividad social \\
\hline 52 & Chiclayo (Tumán) & Lambayeque & $13 / 6 / 2017$ & $04 / 7 / 2018^{31}$ & 9 & 390 & PNP & Conflictividad social \\
\hline \multirow{2}{*}{53} & San Román (Juliaca) & Puno & \multirow{2}{*}{ 20/7/2017 } & \multirow{2}{*}{$18 / 8 / 2017$} & \multirow{2}{*}{0} & \multirow{2}{*}{30} & \multirow{2}{*}{ PNP } & \multirow{2}{*}{ Conflictividad social } \\
\hline & Cusco (Wanchaq y San Sebastián) & Cusco & & & & & & \\
\hline 54 & $\begin{array}{l}\text { Cotabambas (Chalhuahuacho, } \\
\text { Haquira y Mara) } 32\end{array}$ & Apurímac & $17 / 8 / 2017$ & $13 / 1 / 2018$ & 4 & 150 & PNP & Conflictividad social \\
\hline
\end{tabular}




\begin{tabular}{|c|c|c|c|c|c|c|c|c|}
\hline EE & Provincias & Regiones & $\begin{array}{l}\text { Fecha } \\
\text { de inicio }\end{array}$ & $\begin{array}{l}\text { Fecha } \\
\text { de fin }\end{array}$ & Prórrogas & Días & Control & Motivo \\
\hline \multirow[b]{2}{*}{55} & Huanta (Luricocha) & Ayacucho & \multirow[b]{2}{*}{$16 / 9 / 2017$} & \multirow[b]{2}{*}{$5 / 10 / 2017$} & \multirow[b]{2}{*}{0} & \multirow[b]{2}{*}{20} & \multirow[b]{2}{*}{ FFAA } & \multirow[b]{2}{*}{ Terrorismo } \\
\hline & $\begin{array}{l}\text { Tayacaja (San Marcos de Rocchac, } \\
\text { Huaribamba, Pazos, Acraquia, } \\
\text { Ahuaycha, Daniel Hernández y } \\
\text { Colcabamba) y Churcampa }\end{array}$ & Huancavelica & & & & & & \\
\hline \multirow{3}{*}{56} & \multirow{3}{*}{$\begin{array}{l}\text { Corredor vial Apurímac-Cusco- } \\
\text { Arequipa, con una longitud aproxi- } \\
\text { mada de } 482.200 \mathrm{~km} .\end{array}$} & Apurímac & \multirow{3}{*}{$12 / 1 / 2018$} & \multirow{3}{*}{$11 / 6 / 2018^{33}$} & \multirow{3}{*}{3} & \multirow{3}{*}{150} & \multirow{3}{*}{ PNP } & \multirow{3}{*}{ Conflictividad social } \\
\hline & & Cusco & & & & & & \\
\hline & & Arequipa & & & & & & \\
\hline 57 & Tayacaja (Quichuas y Pichos) & Huancavelica & $31 / 1 / 2018$ & $30 / 6 / 2018$ & 2 & 150 & PNP & Conflictividad social \\
\hline 58 & Putumayo & Loreto & $15 / 7 / 2018$ & $13 / 9 / 2018$ & 0 & 60 & PNP & $\begin{array}{l}\text { Criminalidad } \\
\text { transfronteriza }\end{array}$ \\
\hline \multirow{3}{*}{59} & \multirow{3}{*}{$\begin{array}{l}\text { Corredor vial Apurímac-Cusco- } \\
\text { Arequipa, con una longitud aproxi- } \\
\text { mada de } 482.200 \mathrm{~km}^{34}\end{array}$} & Apurímac & \multirow{3}{*}{$30 / 8 / 2018$} & \multirow{3}{*}{ 27/1/2019 } & \multirow{3}{*}{4} & \multirow{3}{*}{150} & \multirow{3}{*}{ PNP } & \multirow{3}{*}{ Conflictividad social } \\
\hline & & Cusco & & & & & & \\
\hline & & Arequipa & & & & & & \\
\hline 60 & Putumayo & Loreto & 28/11/2018 & 29/11/2018 & 0 & 60 & PNP & $\begin{array}{l}\text { Criminalidad } \\
\text { transfronteriza }\end{array}$ \\
\hline
\end{tabular}

1 Derogado por el Decreto Supremo 054-2002-PCM antes de que termine el plazo.

2 El Decreto Supremo 062-2003-PCM concluye el estado de emergencia en el territorio nacional con excepción de las regiones de Junín, Ayacucho y Apurímac, y en la provincia de La Convención (Cusco), en donde se prorroga por 30 días. El Decreto Supremo 070-2003-PCM amplía a la provincia de Tayacaja (Huancavelica).

3 Si bien debió terminar el 26 de agosto de 2003, los Decretos Supremos 062-2003-PCM y 070-2003-PCM empezaron un día antes que venza el plazo. 4 Si bien diversas resoluciones supremas entregaron el control del orden interno a las Fuerzas Armadas, lo hicieron — desde el inicio — en sólo ciertas regiones o provincias del total declarado en emergencia.

5 A pesar de que el estado de emergencia declarado en todo el territorio nacional tuvo una justificación a partir de la conflictividad social, cuando se limitó a ciertas provincias en su primera prórroga, el motivo cambió a ser las facciones terroristas que operaban en aquellas localidades.

6 Si bien debió terminar el 26 de noviembre de 2003, la prórroga (Decreto Supremo 083-2003) empezó un día antes.

7 El Decreto Supremo 081-2003-PCM excluye las provincias de Andahuaylas y Chincheros (Apurímac).

8 Si bien debió terminar el 15 de mayo de 2006, el Decreto Supremo 003-2004-PCM empezó un día antes que venza el plazo.

9 El Decreto Supremo 072-2004-PCM amplía a los distritos de Ollachea y Ayapata, provincia de Carabaya (Puno).

10 Si bien debió terminar el 1 de marzo de 2005, el Decreto Supremo 089-2004-PCM empezó dos días antes.

11 Si bien debió terminar el 15 de junio de 2007, el Decreto Supremo 006-2006-PCM empezó dos días antes, y los decretos 030-2006-PCM, 069-2006-

PCM y 088-2006-PCM un día después. Por lo tanto, al final hay un día que no habría estado de emergencia: el 18 de diciembre de 2006.

12 El Decreto Supremo 065-2007-PCM limitó la provincia de La Convención a los distritos de Kimbiri, Pichari y Vilcabamba.

13 El Decreto Supremo 044-2007-PCM añadió el distrito de Comas de la provincia de Concepción y el distrito de Pariahuanca de la provincia de Huancayo.

14 Si bien debió terminar el 16 de abril de 2007, se prorrogó el estado de emergencia un día antes que acabe el plazo, por lo que el 1 de abril se repite el día.

15 Derogado por el Decreto Supremo 059-2007-PCM antes de que termine el plazo.

16 El Decreto Supremo 086-2007-PCM limita el territorio a los distritos de San Buenaventura y Cholón de la provincia de Marañón, distrito del Monzón de la provincia de Huamalíes (Huánuco).

17 Si bien debió terminar el 28 de agosto de 2009, el Decreto Supremo 041-2009-PCM inició un día después del vencimiento del plazo. Por lo tanto, hubo un día que no hay emergencia por error de cálculo: el 30 de junio de 2009.

18 Derogado por el Decreto Supremo 061-2008-PCM antes de que termine el plazo.

19 Derogado por el Decreto Supremo 007-2009-PCM antes de que termine el plazo.

20 El Decreto Supremo 035-2009-PCM amplió a todo el departamento de Amazonas, a la provincia del Datem del Marañón (Loreto), así como a las provincias de Jaén y San Ignacio (Cajamarca).

21 Derogado por el Decreto Supremo 039-2009-PCM antes de que termine el plazo.

22 La Resolución Suprema 192-2009-DE-SG otorgó el control del orden interno a las Fuerzas Armadas durante el resto del estado de emergencia.

23 Si bien debió terminar el 7 de septiembre de 2011, la prórroga del Decreto Supremo 097-2010-PCM inició un día antes que venza el plazo.

24 Derogado por el Decreto Supremo 080-2010-PCM antes de que termine el plazo.

25 Si bien debió terminar el 22 de junio de 2015, la prórroga del Decreto Supremo 99-2013-PCM inició un día antes que venza el plazo.

26 El Decreto Supremo 002-2016-PCM cambia el control del orden interno a la Policía Nacional del Perú.

27 Derogado por el Decreto Supremo 096-2001-PCM antes de que termine el plazo. 
28 Derogado por el Decreto Supremo 076-2016-PCM antes de que termine el plazo.

29 El Decreto Supremo 003-2016-PCM cambia el control del orden interno a la Policía Nacional del Perú.

30 Mediante Decreto Supremo 097-2017-PCM se aumentan algunos distritos en Huancavelica. Mediante Decreto Supremo 035-2018-PCM se excluyen los distritos de Acraquia y Ahuaycha de la provincia de Tayacaja (Huancavelica). Mediante Decreto Supremo 058-2018-PCM se excluyen algunos otros distritos o provincias en Huancavelica.

31 Si bien debió terminar el 7 de julio de 2018, el Decreto Supremo 024-2018-PCM empezó a un día antes y el Decreto Supremo 048-2018-PCM dos días antes de que termine el plazo.

32 El Decreto Supremo 101-2017-PCM excluye al distrito de Haquira de la provincia de Cotabambas (Apurímac).

33 Si bien debió terminar el 10 de junio de 2018, el Decreto Supremo 015-2018-PCM empezó tres días antes, el 025-2018-PCM dos días antes y el 037-2018-PCM empezó cuatro días después.

34 El Decreto Supremo 100-2018-PCM limita el territorio desde el kilómetro 130 (Ref. Sector Muyu Orcco) hasta el kilómetro 160 (Ref. Sector Tiendayoc), de la Ruta Nacional PE-3SY, que comprende el distrito de Colquemarca de la provincia de Chumbivilcas (Cusco).

Fuente: Elaboración propia. 
El Anuario de Derechos Humanos es una publicación semestral de referencia y consulta en materia de derechos humanos y campos afines. Busca ser un espacio de discusión de los temas centrales en el ámbito nacional e internacional sobre derechos humanos. Es publicado desde 2005 por el Centro de Derechos Humanos de la Facultad de Derecho de la Universidad de Chile.

\author{
EDITORA \\ Claudia Iriarte Rivas \\ ciriarter@derecho.uchile.cl \\ SITIO WEB \\ anuariocdh.uchile.cl \\ CORREO ELECTRÓNICO \\ anuario-cdh@derecho.uchile.cl \\ LICENCIA DE ESTE ARTÍCULO \\ Creative Commons Atribución Compartir Igual 4.o Internacional
}

\author{
\% \\ La edición de textos, el diseño editorial \\ y la conversión a formatos electrónicos de este artículo \\ estuvieron a cargo de Tipográfica \\ (www.tipografica.io)
}

